\title{
Ontogeny of Recognition Specificity and Functionality for the Broadly Neutralizing Anti-HIV Antibody 4E10
}

\section{Citation}

Finton, K. A. K., D. Friend, J. Jaffe, M. Gewe, M. A. Holmes, H. B. Larman, A. Stuart, et al. 2014. "Ontogeny of Recognition Specificity and Functionality for the Broadly Neutralizing Anti-HIV Antibody 4E10." PLoS Pathogens 10 (9): e1004403. doi:10.1371/journal.ppat.1004403. http:// dx.doi.org/10.1371/journal.ppat.1004403.

\section{Published Version}

doi:10.1371/journal.ppat.1004403

\section{Permanent link}

http://nrs.harvard.edu/urn-3:HUL.InstRepos:13347649

\section{Terms of Use}

This article was downloaded from Harvard University's DASH repository, and is made available under the terms and conditions applicable to Other Posted Material, as set forth at http:// nrs.harvard.edu/urn-3:HUL.InstRepos:dash.current.terms-of-use\#LAA

\section{Share Your Story}

The Harvard community has made this article openly available.

Please share how this access benefits you. Submit a story.

Accessibility 


\title{
Ontogeny of Recognition Specificity and Functionality for the Broadly Neutralizing Anti-HIV Antibody 4E10
}

\author{
Kathryn A. K. Finton ${ }^{1}$, Della Friend ${ }^{1}$, James Jaffe ${ }^{1}$, Mesfin Gewe ${ }^{1}$, Margaret A. Holmes ${ }^{1 \dagger}$, \\ H. Benjamin Larman ${ }^{2}$, Andrew Stuart ${ }^{3}$, Kevin Larimore ${ }^{4}$, Philip D. Greenberg ${ }^{4,5,6}$, Stephen J. Elledge ${ }^{2}$, \\ Leonidas Stamatatos ${ }^{3,7}$, Roland K. Strong ${ }^{1 *}$
}

1 Division of Basic Sciences, Fred Hutchinson Cancer Research Center, Seattle, Washington, United States of America, 2 Department of Genetics, Harvard University Medical School, and Division of Genetics, Howard Hughes Medical Institute, Brigham and Women's Hospital, Boston, Massachusetts, United States of America, 3 Seattle Biomedical Research Institute, Seattle, Washington, United States of America, 4 Department of Immunology, University of Washington, Seattle, Washington, United States of America, 5 Department of Medicine, University of Washington, Seattle, Washington, United States of America, 6 Program in Immunology, Cancer Research Division, Fred Hutchinson Cancer Research Center, Seattle, Washington, United States of America, 7 Department of Global Health, University of Washington, Seattle, Washington, United States of America

\begin{abstract}
The process of antibody ontogeny typically improves affinity, on-rate, and thermostability, narrows polyspecificity, and rigidifies the combining site to the conformer optimal for binding from the broader ensemble accessible to the precursor. However, many broadly-neutralizing anti-HIV antibodies incorporate unusual structural elements and recognition specificities or properties that often lead to autoreactivity. The ontogeny of $4 \mathrm{E} 10$, an autoreactive antibody with unexpected combining site flexibility, was delineated through structural and biophysical comparisons of the mature antibody with multiple potential precursors. 4E10 gained affinity primarily by off-rate enhancement through a small number of mutations to a highly conserved recognition surface. Controverting the conventional paradigm, the combining site gained flexibility and autoreactivity during ontogeny, while losing thermostability, though polyspecificity was unaffected. Details of the recognition mechanism, including inferred global effects due to 4E10 binding, suggest that neutralization by 4E10 may involve mechanisms beyond simply binding, also requiring the ability of the antibody to induce conformational changes distant from its binding site. $4 \mathrm{E} 10$ is, therefore, unlikely to be re-elicited by conventional vaccination strategies.
\end{abstract}

Citation: Finton KAK, Friend D, Jaffe J, Gewe M, Holmes MA, et al. (2014) Ontogeny of Recognition Specificity and Functionality for the Broadly Neutralizing AntiHIV Antibody 4E10. PLoS Pathog 10(9): e1004403. doi:10.1371/journal.ppat.1004403

Editor: Georgia Tomaras, Duke University Medical Center, United States of America

Received February 5, 2014; Accepted August 16, 2014; Published September 25, 2014

Copyright: (c) 2014 Finton et al. This is an open-access article distributed under the terms of the Creative Commons Attribution License, which permits unrestricted use, distribution, and reproduction in any medium, provided the original author and source are credited.

Funding: This work was supported by the National Institute of Allergy and Infectious Diseases of the National Institutes of Health under award number P01A1094419 (LS \& RKS) and the National Cancer Institute of the National Institutes of Health under award number R01CA033084 (PDG). This research was also conducted as part of the Collaboration for AIDS Vaccine Discovery with support to RKS and PDG from the Bill and Melinda Gates Foundation. KAKF was supported in part by Public Health Service National Research Service Award T32GM008268, from the National Institute of General Medical Sciences of the National Institutes of Health. SJE is an Investigator with the Howard Hughes Institute. The content is solely the responsibility of the authors and does not necessarily represent the official views of the National Institutes of Health. The funders had no role in study design, data collection and analysis, decision to publish, or preparation of the manuscript.

Competing Interests: The authors have declared that no competing interests exist.

* Email: rstrong@fhcrc.org

$\dagger$ Deceased.

\section{Introduction}

An effective HIV vaccine will likely need to elicit broadlyneutralizing antibodies (bnAbs) that target the viral envelope protein (Env) as part of a protective immune response [1-6]. Envderived and reverse-engineered immunogen-based vaccines, however, have consistently failed to elicit bnAbs. Possible explanations include that: (1) immunogens may be unable to bind germlineencoded precursors (GEPs) of bnAbs with sufficient affinity to initiate $\mathrm{B}$ cell activation and affinity maturation, which has a $\sim$ micromolar threshold [7-9]; (2) rearranged $\mathrm{V}_{\mathrm{H}}$ and $\mathrm{V}_{\mathrm{L}}$ genes compatible with the development of bnAbs may not be common in human or animal model vaccinee GEP repertoires; (3) some bnAbs are autoreactive, which hinders their elicitation through self-tolerance mechanisms; (4) the unusual characteristics inherent to bnAbs, such as long complementarity determining regions (CDRs), functionally-required polyspecificity, and a high degree of somatic mutation (typically observed in Abs elicited in response to chronic infections, including bnAbs), may not be easily achieved through conventional vaccination strategies; (5) imperfect immunogens may elicit off-target (non-neutralizing or non-Env) or humoral responses with limited breadth; and, finally, (6) neutralization mechanisms may involve complexities beyond simply binding a particular epitope on Env (e.g., inducing specific conformational changes), which may be difficult to recapitulate, since selective expansion of particular B cell clones is based solely on BCR binding properties, not higher-order functionalities $[10,11]$.

The bnAb 4E10, the focus of our studies, has a conserved, linear epitope (core epitope: ${ }^{671} \mathrm{NWF}^{\mathrm{D}} / \mathrm{N}_{\mathrm{IT}}{ }^{676}$ ) immediately adjacent to the viral membrane in the Env gp41 subunit membrane proximal external region (MPER) [12,13]. While 4E10 displays admirable breadth [14], has been the target of a successful design effort to reverse-engineer tight-binding immunogens [15], has recognizable 


\section{Author Summary}

4E10 is an antibody that neutralizes a broad variety of HIV strains. However, 4E10 is uncommon in infected patients and has not been successfully elicited by any vaccine approach attempted. Hurdles to re-eliciting 4E10 include the accumulation of many mutations during development, demonstrated reactivity against host proteins and significant structural flexibility. Lacking a confirmed sequence for precursors of 4E10, we studied the recognition and biophysical properties of an ensemble of eight of the likeliest candidates. Surprisingly, 4E10 gained host reactivity and structural flexibility, but lost stability during development when compared to candidate precursors. However, recognition of HIV was remarkably conserved, despite a considerable improvement in binding. Since these results run counter to those expected from conventional vaccination protocols, $4 \mathrm{E} 10$ is unlikely to serve as the basis of a useful HIV vaccine.

GEPs present at finite frequencies in human naïve repertoires [16], and arguably does not require a high degree of polyspecificity to neutralize HIV [17,18], its viability as a vaccine target is hampered by limited potency, demonstrated autoreactivity and exceptional combining site flexibility $[17,19,20]$. The neutralization mechanism of $4 \mathrm{E} 10$ also has not been clearly defined and may involve higher order effects [17,21,22]. The ontogeny of 4E10, therefore, must be elucidated in order to understand how these properties were acquired and to what degree they impose constraints that might hinder re-elicitation by vaccination.

Mutations acquired during $\mathrm{Ab}$ maturation occur preferentially in the CDRs, which make up the six loops (CDRs 1, 2, and 3 on the heavy (HCDRs) and light (LCDRs) chains) comprising the combining site [23,24]. CDRs are responsible for the majority of direct contacts to an antigen, as opposed to the intervening framework regions (FWRs), which form the immunoglobulin $\beta$ sheet structure stabilizing the combining site, helping define CDR loop conformations. While CDR mutations are typically thought to more directly affect antigen binding and neutralization, bnAbs consistently depend on FWR substitutions to a surprising degree, though $4 \mathrm{E} 10$ is an exception to this exception [4]. bnAbs are notorious for their high degree of somatic hypermutation, the product of a long process of affinity maturation against a rapidly mutating virus during a persistent, chronic infection [25]. While typical affinity-matured Abs have acquired 15 to $20 \mathrm{~V}_{\mathrm{H}}$ mutations, bnAbs accumulate up to $100 \mathrm{~V}_{\mathrm{H}}$ mutations [4]. These mutations are crucial because reversion to germline sequences drastically reduces epitope affinity and neutralization potency and breadth. In many cases, bnAb GEPs are unable to bind Env, though the actual eliciting isolate may not be known [26-31]. In addition, bnAbs can contain extraordinarily long HCDR 3 s, up to 33 residues long versus an average of 13 for non-HIV bnAbs [32,33]. Using phylogenetically-inferred GEP sequences [16,34] (Fig. 1), 4E10 has acquired between 33 and 35 mutations during maturation, 20 to 22 in $\mathrm{V}_{\mathrm{H}}$, depending on gene segment selection, and 13 in $\mathrm{V}_{\mathrm{L}}$, and has an HCDR 322 residues long, values at the less exceptional end of the $\mathrm{bnAb}$ spectrum and not unheard of for conventional Abs.

Affinity-matured Abs display univalent equilibrium binding constants $\left(K_{\mathrm{D}}\right)$ for their cognate antigens, typically ranging from $10^{-6}$ to $10^{-10} \mathrm{M}$, that are orders-of-magnitude stronger than their GEPs [35]. Multiple approaches, including computational analyses and biophysical comparisons of affinity-matured Abs and their associated GEPs, have generated a consensus model for the molecular mechanism of affinity maturation [36-47], perhaps better understood as binding optimization, that traces its roots back to Pauling [48]. In the consensus model, the antigen specificities of the naive, germline-encoded repertoire, while diverse and extensive, are further extended by encoding a high degree of polyspecificity into GEPs. This is accomplished partly through increased combining site plasticity in GEPs, more formally stated as the ability of GEP CDRs to dynamically sample a broader ensemble of structural conformers. In response to immunogen stimulation, Ab binding properties are iteratively optimized through cycles of somatic hypermutation and selection, resulting in improved binding affinities, kinetics and thermodynamics. While mutations have been observed to improve or add direct contacts to antigen, typically improving enthalpies of interaction and off-rates $\left(k_{\mathrm{d}}\right)$, a majority of measurably favorable mutations do not directly contact antigen. These mutations indirectly optimize binding by: (1) increasing shape complementarity

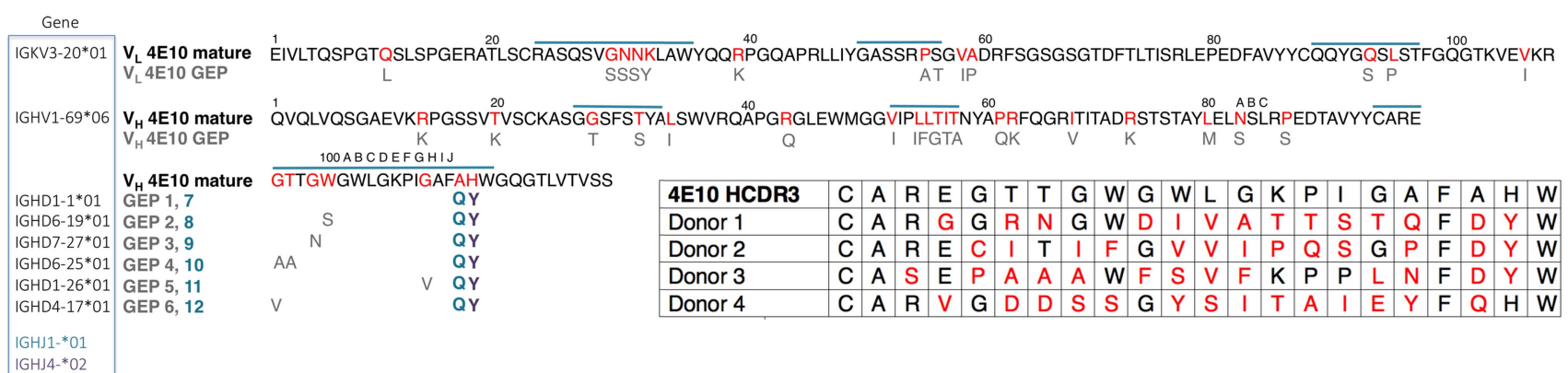

Figure 1. Prediction of an ensemble of $4 E 10$ GEPs. Sequences of $4 E 10 V_{L}$ (top line) and $V_{H}$ (bottom two lines) domains are shown, with CDRs indicated by a blue overscore. Predicted somatic mutations are colored red in the $4 \mathrm{E} 10$ sequence, and the corresponding unmutated GEP residues are shown below in grey (unchanged positions are not shown for clarity). All GEP $V_{\mathrm{L}}$ domains are comprised of the IGKV3-20*01/IGKJ1*01 gene segment combination. Each GEP $V_{H}$ domain comprises the IGHV1-69*06 V gene segment plus one of six D gene segments (listed to the left of the corresponding GEP in the blue boxed field), and either the IGHJ4*02 (resulting sequence differences shown in purple and bolded) or IGHJ1*01 (resulting sequence difference shown in blue and bolded) gene segment, yielding an ensemble of 12 GEPs in toto. GEP shorthand numbering is shown in grey (GEPs 1 to 6) and blue (GEPs 7 to 12) beside the corresponding D plus J gene segment combination sequence differences from 4E10, occurring in HCDR3. Inset (lower right): HCDR3 sequences from candidate 4E10 GEPs, determined through deep sequencing of naïve B cell germline $\mathrm{IgH}$ genes from four uninfected individuals [16], show the degree of variability seen in potential 4E10 precursors present in naïve repertoires. Each germline rearrangement uses the IGHV1-69 and IGJH1 or IGJH4 gene segments. Amino acids in red designate sequence differences between GEP and 4E10. The number of nucleotide changes needed to achieve these somatic mutations is 16 for donor 1,17 for donor 2 and 18 for donors 3 and 4 . doi:10.1371/journal.ppat.1004403.g001 

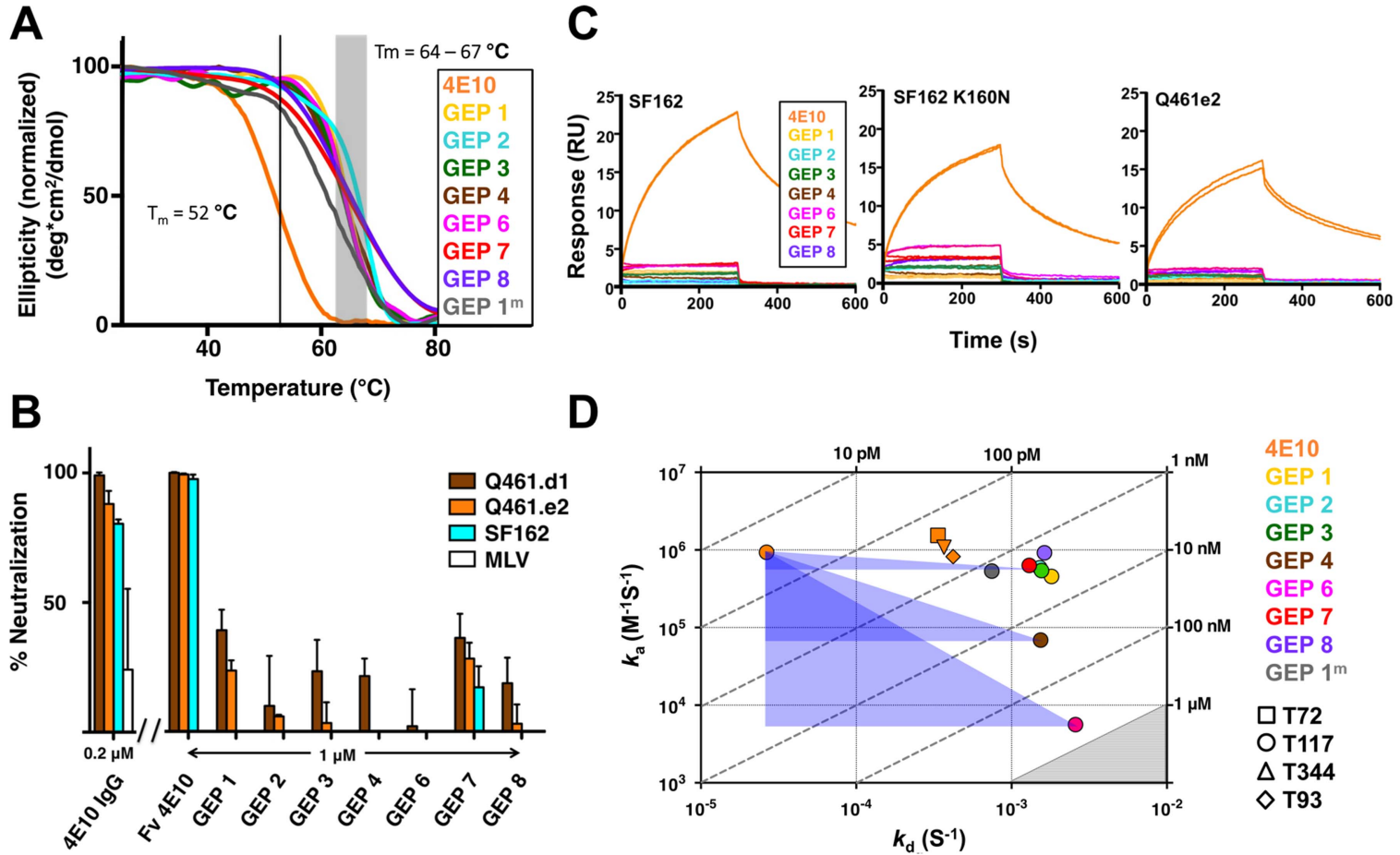

D

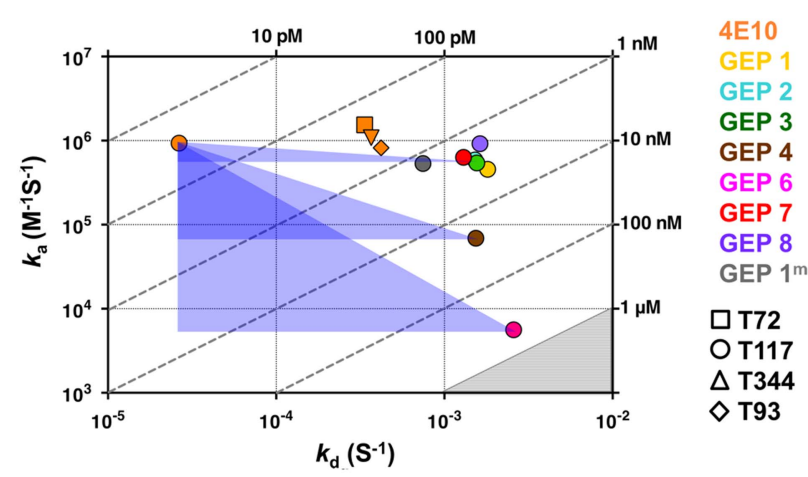

Figure 2. Biophysical and functional characterization of an ensemble of 4E10 GEPs. (A) CD melting curves are shown for $4 E 10$ and GEPs with $\mathrm{T}_{\mathrm{m}}$ values, determined as the inflection point of the sigmoidal melting curve, indicated by a black line (4E10) or a shaded grey box (GEPs). (B) Neutralization potencies are shown for 4E10 IgG $(0.2 \mu \mathrm{M})$, 4E10 Fv and GEPs (1 $\mu \mathrm{M})$ against clade A (Q461.d1, Q461.e2) and B (SF162) HIV-1 isolates using standard TZM-bl assays. (C) Double-referenced SPR sensorgrams are shown for the binding of 4E10 and GEPs (300 nM duplicates) interacting with chipcoupled gp $140_{3}$. (D) $K_{\mathrm{D}} \mathrm{S}$ for the interaction of $4 \mathrm{E} 10$ or GEPs with ES T117 are plotted as $k_{\mathrm{a}}$ vs. $k_{\mathrm{d}}$, with $K_{\mathrm{D}}$ isotherms indicated by dashed lines and labeled. Due to weak binding and fast kinetics, $K_{\mathrm{D}}$ s between GEPs and the T72, T344, and T93 ESs could only be analyzed by equilibrium measurements; their values range from 1 to $10 \mu \mathrm{M}$, falling within the grey shaded region. The purple triangles show the T117 affinity shift between $4 \mathrm{E} 10$ and GEPs, with the sides parallel to the $X$ and $Y$ axes of each triangle highlighting the association and dissociation rate components, respectively.

doi:10.1371/journal.ppat.1004403.g002

between paratopes and epitopes through more global effects on structure; (2) increasing antibody stability, typically measured as solution thermostabilities $\left(\mathrm{T}_{\mathrm{m}}\right)$, thus compensating for deleterious effects of other mutations that improve affinity; and (3) structurally rigidifying the combining site conformer optimal for binding antigen from the accessible ensemble. Rigidifying the combining site can affect measured interaction parameters in different ways depending on the mechanism of binding. The two mechanistic extremes are known as "conformer-selection" and "instructive-encounter", or "induced-fit", binding. In conformerselection mode, binding does not occur until the compatible conformer is adopted. Rigidification of the binding site through mutation then typically improves entropies of interaction and onrates $\left(k_{\mathrm{a}}\right)$. In instructive-encounter mode, initial binding occurs to sub-optimal conformers which affects the rate of interchange with the optimal conformer. Rigidification of the binding site through mutation then typically improves affinity through changes distributed over $k_{\mathrm{d}}$ and $k_{\mathrm{a}}$. However, the consensus of studies of binding proteins and enzymes suggests that conformer selection is the preeminent recognition mechanism [49].

Surprisingly, comparisons of the bound and unbound structures of $4 \mathrm{E} 10$ revealed that this affinity-matured bnAb incorporates considerable HCDR conformational flexibility [17], in excess of what has been observed in most other antibodies, mature or GEP, suggesting that the ontogeny of $4 \mathrm{E} 10$ may be an exception to the consensus model and may pose unique challenges as a vaccine target. In order to fully understand the ontogeny of this unique $\mathrm{bnAb}$ and consequences for vaccine development, we characterized the unbound and complex crystal structures, and the functional and binding properties, of 4E10 and an ensemble of its most likely GEPs. GEPs showed detectable, but extremely weak, binding to soluble Env gp140s and extremely limited neutralization potency, though some reverse engineered epitope-scaffolds (ESs) showed robust GEP affinities, well above the B cell activation threshold. 4E10 and GEP paratopes displayed a remarkable degree of structural conservation in the antigen-bound state, with little improvement in overall shape complementarity. Multi-log improvements in affinity for ESs were the result of improved off-rates or combined improvements in onand off-rates, with a small number of enhanced contacts to antigen observed in the crystal structures. However, minimal mutations of GEP sequences to include these enhanced direct contacts only marginally increases affinity. FWR mutations had little discernable effect on global or local structure. Controverting the consensus model of ontogeny, 4E 10 thermostability was appreciably worse than its GEPs; while 4E10 and GEPs displayed similarly constrained $\mathrm{V}_{\mathrm{H}} / \mathrm{V}_{\mathrm{L}}$ interdomain movements upon binding, 4E10 maturation involved negligible combining site rigidification, with both $4 \mathrm{E} 10$ and GEP HCDRs sampling extensive conformer ensembles. The narrowing of polyspecificity assumed to concur with maturation was not observed with 4E10, as both 4E10 and its GEPs showed similar patterns of limited polyspecificity to a phage-displayed human peptidome (Phage Immunoprecipitation Sequencing; PhIP-Seq) [50]. While 4E10 is demonstrably autoreactive, GEPs exhibited a distinct profile of autoantigen recognition by PhIP-Seq. When combined, these results inform efforts to re-elicit $4 \mathrm{E} 10$ by vaccination and its mechanism of neutralization. 

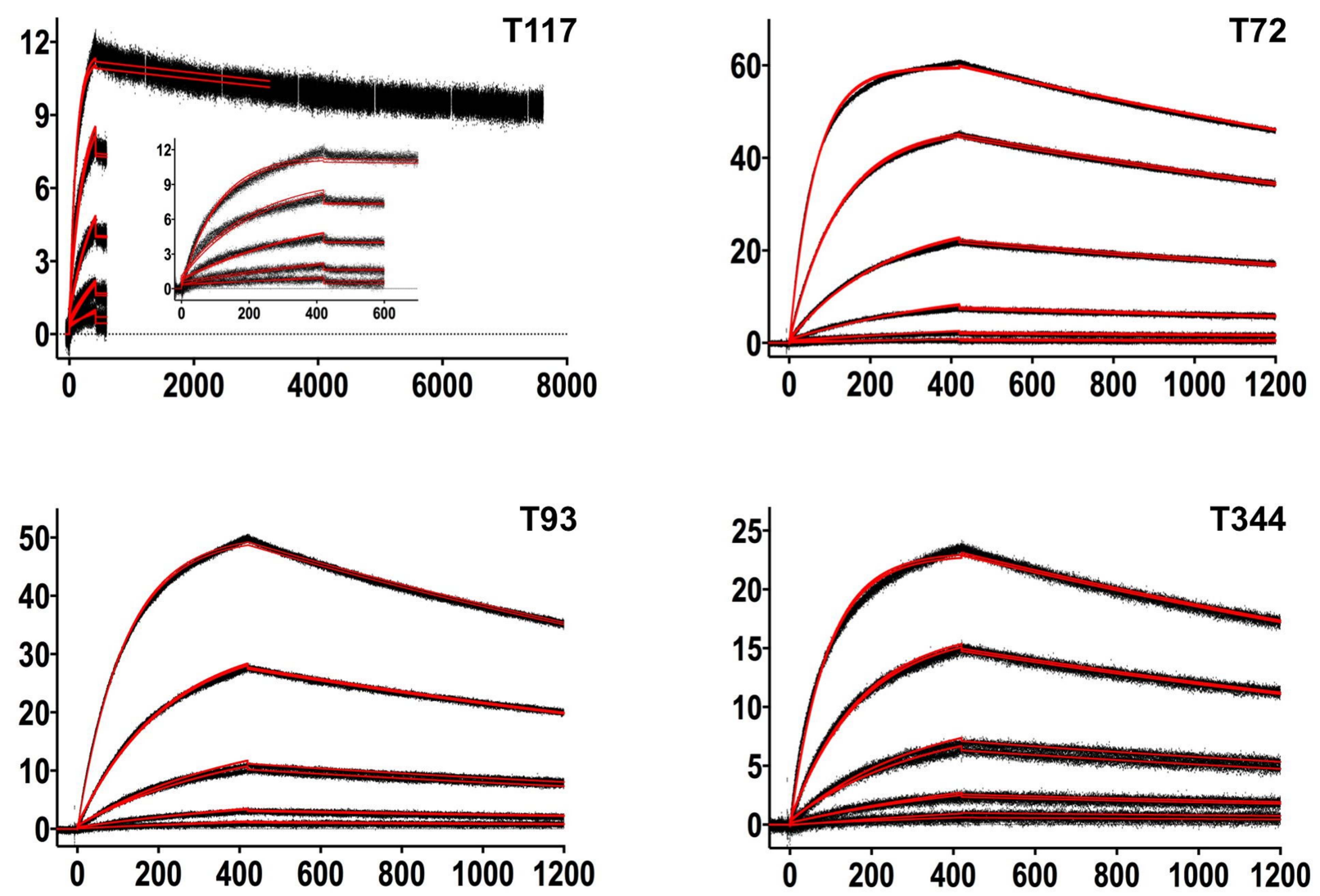

Figure 3. SPR sensorgrams of the interactions between 4E10 and the indicated ESs are shown. Time (in seconds) is plotted on the $x$-axis and SPR response (in RUs) is plotted on the y-axis. Double-referenced binding data are shown in black with corresponding kinetics fits to the data shown in red. Details of the experiments are given in Table 1.

doi:10.1371/journal.ppat.1004403.g003

\section{Results}

Prediction of an ensemble of likeliest GEP sequences

Lacking access to the original donor, identification of a single GEP sequence with high confidence for many bnAbs, including $4 \mathrm{E} 10$, is complicated by extensive editing and TdT N-nucleotide insertion during rearrangement [26], leading to our decision to study an ensemble of the 12 likeliest candidates (Fig. 1). Due to the prediction that the sequence differences introduced by alternate heavy chain $\mathrm{J}$ gene segments may not affect any discernable GEP property, the initial ensemble was limited to eight GEPs $(\mathrm{IGHJ} 4 * 02$ paired with all six D segments plus IGHJ1*01 paired with IGHD1-1*01 and IGHD6-19*01), with the intention of generating additional GEPs if the IGHJ $4 * 02$ / IGHJ $1 * 01$ substitution exhibited any differences in structure or binding properties on the IGHD1-1*01 or IGHD6-19*01 backgrounds. These eight GEPs also recapitulated some of the variability seen in potential 4E10 GEPs identified by deep sequencing of uninfected individuals (Fig. 1) [16], providing an additional justification for studying the ensemble. However, GEPs in our ensemble differed from one another by no more than four mutations, though the mutations were quite nonconservative.

\section{GEP protein production and validation}

GEPs were engineered as cleavable, single-chain, variable domain cassette $\left(\mathrm{FV} ; \mathrm{V}_{\mathrm{H}}+\mathrm{V}_{\mathrm{L}}\right)$ constructs to ease expression, analysis, and crystallization and to prevent monobody-diabody interchange, following protocols developed for $4 \mathrm{E} 10$ [18]. The prior study confirmed that these $\mathrm{Fv}_{\mathrm{V}}$ constructs retained the structural and binding properties of Fab fragments of intact 4E10. All eight GEP Fvs expressed at high levels as bacterial inclusion bodies and, in all but one case (GEP 5), were refolded in vitro with what in our experience were exceptionally high efficiencies of 20 to $40 \%$. GEP 5 was not included in subsequent experiments because its extremely poor in vitro refolding efficiency suggested that this was not a viable pairing. GEP constructs were stable and monodisperse in solution, running exclusively as monomers by size exclusion chromatography (SEC). Reduced/non-reduced PAGE analysis of GEPs confirmed purity and proper disulfide bond formation. GEP $\mathrm{T}_{\mathrm{m}}$ values (Fig. 2A), determined by circular dichroism (CD) spectroscopy as previously described [18], narrowly ranged from $64.2^{\circ} \mathrm{C}$ to $67.0^{\circ} \mathrm{C}$, showing that GEP Fvs were well folded, but had even higher $\mathrm{T}_{\mathrm{m}}$ values than $4 \mathrm{E} 10 \mathrm{Fv}$ $\left(52.8^{\circ} \mathrm{C}\right)$.

GEP neutralization potencies were dramatically reduced

The neutralization potency of GEPs was tested against clade A (Q461.d1, Q461.e2 [51]) and B (SF162 [52]) HIV-1 isolates using standard TZM-bl assays (Fig. 2B) [53]. Overall, GEP FV potencies were markedly reduced in comparison with $4 \mathrm{E} 10 \mathrm{Fv}$. GEPs displayed only very weak and likely insignificant neutralization potencies, though with a trend of greater effect against the clade A isolates, particularly the neutralization-sensitive strain Q461.d1, and with GEP 1 and GEP 7 showing marginally better potencies across tested isolates. 
GEP 1
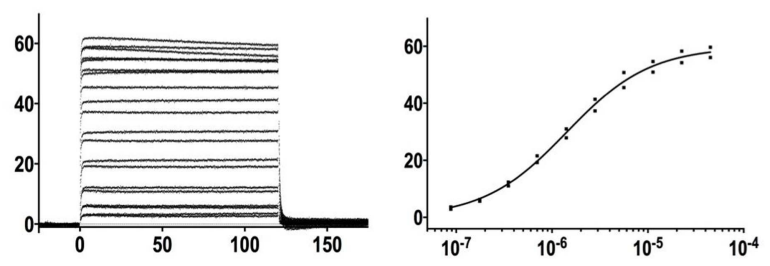

GEP 3
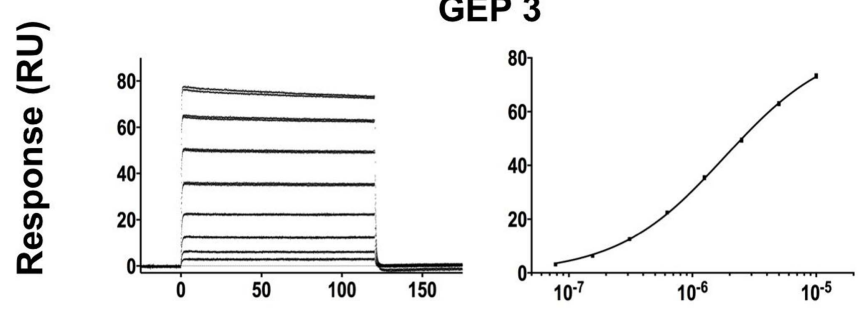

GEP 7
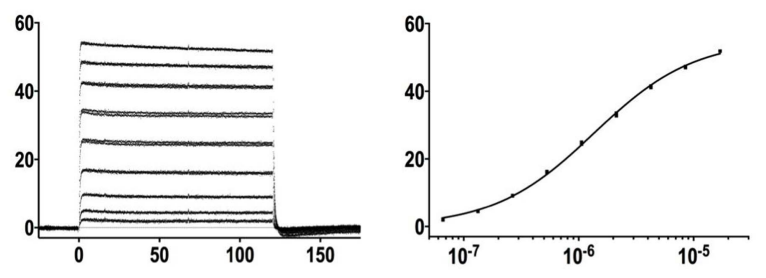

Time (s)
Concentration (M)
GEP 2
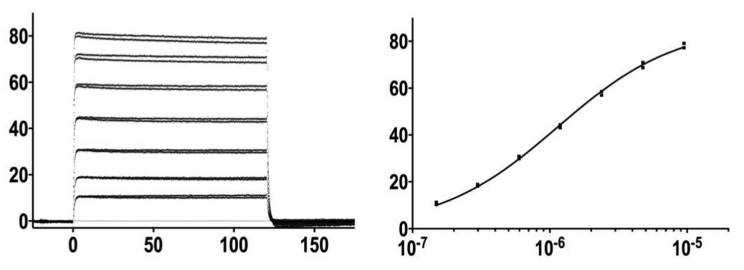

GEP 4
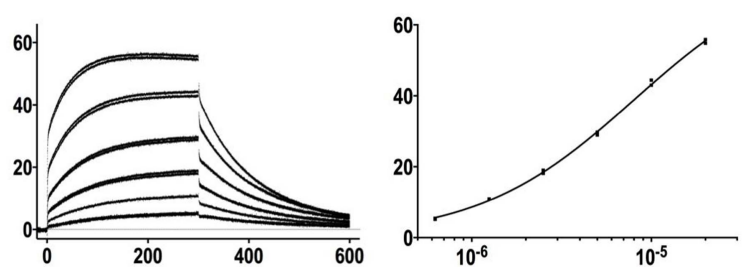

GEP 8

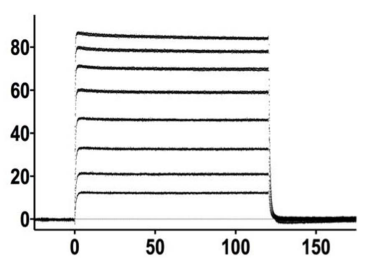

Time (s)

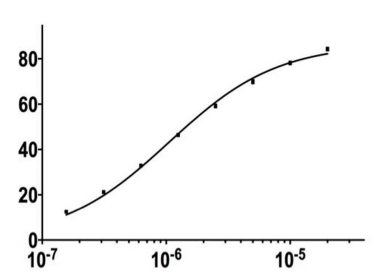

Concentration (M)

Figure 4. SPR sensorgrams of the interactions between ES T72 and the indicated GEPs (left plots) and the analysis of equilibrium responses versus concentration (right plots). Details of the experiments are given in Table 1. doi:10.1371/journal.ppat.1004403.g004

GEPs bound Env proteins and engineered antigens, but with reduced affinities

In order to characterize the change in binding properties during $4 \mathrm{E} 10$ ontogeny, the binding of $4 \mathrm{E} 10$ and GEP Fvs to three (SF162, SF162 ${ }^{\mathrm{K} 160 \mathrm{~N}}$ and Q461.e2) soluble Env gp140 trimers (gp140 3 ) [54] and four engineered 4E10 ES immunogens (T72, T93, T117 and T344) $[15,55]$ was evaluated by surface plasmon resonance (SPR) interaction analysis (Figs. 2C, 2D, Figs. 3-7, Table 1). Isolates and ESs were selected to span a range of binding properties, where previous studies had shown $4 \mathrm{E} 10$ bound a free peptide spanning its linear epitope with a $K_{\mathrm{D}}$ of $12 \mathrm{nM}, \mathrm{SF} 162$ gp $140_{3}$ with a $K_{\mathrm{D}}$ of $98 \mathrm{nM}$, and ESs with $K_{\mathrm{D}}$ s of either $\leq 10$ picomolar (T117) or $\sim 100$ picomolar (T72, T93 and T344) $[15,18,55]$. All seven GEPs showed unquantifiably weak, but detectable binding to chip-coupled clade A (Q461.e2) and clade B (SF162, SF162 ${ }^{\mathrm{K} 160 \mathrm{~N}}$ ) gp $140_{3}$ and $\mathrm{T} 72$, T93, and $\mathrm{T} 344$ in qualitative SPR analyses, with $K_{\mathrm{D}} \mathrm{s}$ all estimated to be well above the $\sim$ micromolar B cell activation threshold. Quantitative SPR analyses of GEPs binding to T117 showed $K_{\mathrm{D}}$ s ranging from the low nanomolar to low micromolar range. 4E10 interactions with ESs ranged from 100- to 10,000-fold stronger than GEPs, which was qualitatively consistent with the observed difference in $4 \mathrm{E} 10$ versus GEP interactions with $\mathrm{gp} 140_{3}$. Since the $\mathrm{GEP} / \mathrm{gp} 140_{3}$ interactions were too weak to quantitate, peptide binding studies were not performed on the expectation that they would also be too weak to measure accurately. Five GEPs $(1,2,3,7$ and 8) bind
T117 with nearly identical behavior, including GEP 1 and GEP 7, which differ only by alternate $\mathrm{J}$ segment utilization, showing that the two incorporated mutations did not affect binding, so no further IGHJ1*01 GEPs were produced for study. GEP 4 and GEP 6, which both incorporate differences from G96H in 4E10 (A or V), showed approximately 10-fold (GEP 4) or 100-fold (GEP 6) reductions in affinity relative to the cluster of other GEPs. Kinetically, the five clustering GEPs $(1,2,3,7$ and 8) showed affinity reductions for $\mathrm{T} 117$ relative to $4 \mathrm{E} 10$ overwhelmingly through faster off-rates $\left(k_{\mathrm{d}} \mathrm{s}\right)$. GEPs 4 and 6 , in addition to comparable increases in $k_{\mathrm{d}}$, also showed progressive reductions in on-rates $\left(k_{\mathrm{a}} \mathrm{s}\right)$.

\section{E10- and GEP-ES complex structures show binding site conservation}

In order to shed light on potential structural differences accounting for reduced GEP binding affinities, crystal structures of GEP 1, 2 and 7 in complex with T117 were determined at resolution values of $2.9 \AA, 1.8 \AA$, and $3.1 \AA$ respectively, rebuilt and refined with good statistics (Table 2), and compared to two reference 4E10/antigen complex structures: $4 \mathrm{E} 10$ bound to an epitope peptide (2FX7.pdb [12]) or a related ES, T88 (3LH2.pdb [15]). Superpositions showed that almost all direct contacts to the core epitope (NWFDIT) and epitope conformation are conserved between 4E10 and GEP complexes to a remarkable degree (Fig. 8, Tables 3 and 4). Only six of the 35 predicted somatic 


\section{GEP 1}
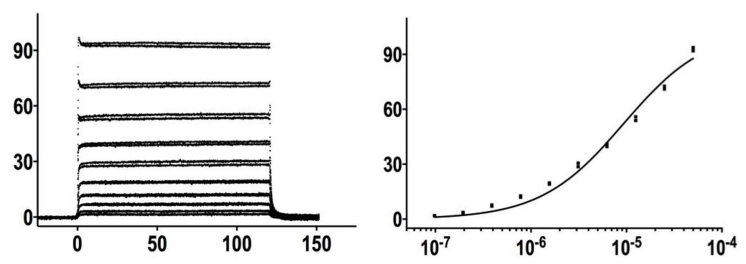

GEP 3
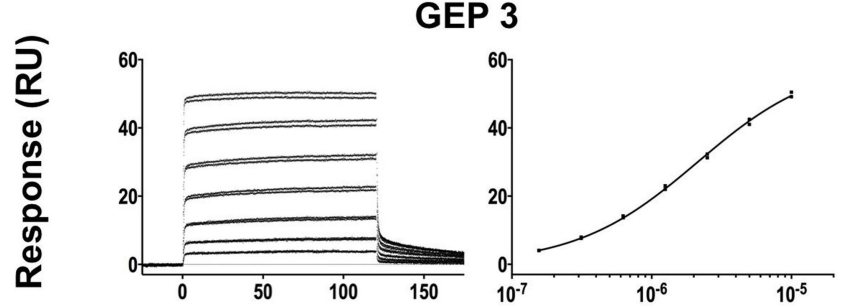

GEP 7

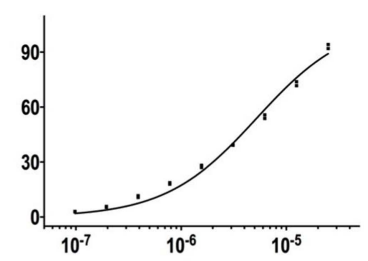

Time (s)
Concentration (M)

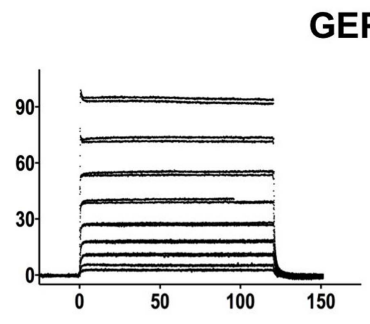

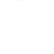

.
\end{abstract}

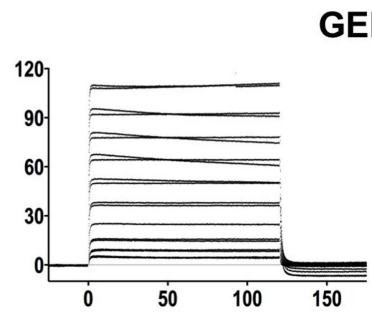

GEP 2

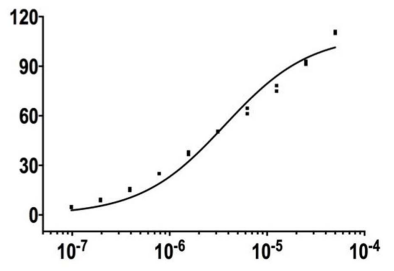



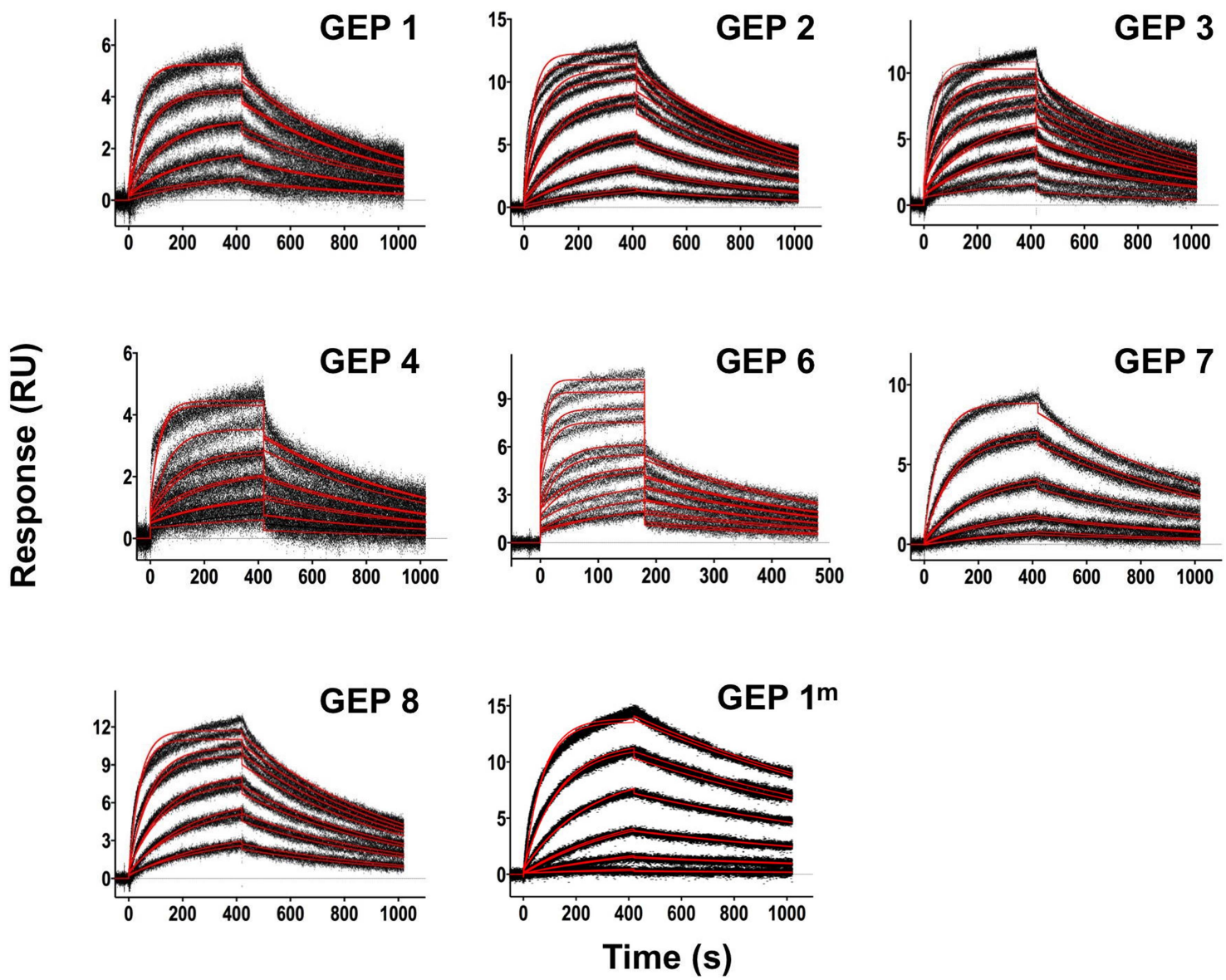

Figure 6. SPR sensorgrams of the interactions between ES T117 and the indicated GEPs are shown. Binding data are shown in black with the kinetic fits to the data shown in red. Details of the experiments are given in Table 1.

doi:10.1371/journal.ppat.1004403.g006

varying non-physiological solution conditions and variable crystal contacts between structures. However, these caveats were minimized by comparing multiple structures with multiple copies per asymmetric unit.

\section{Engineered ESs can make extensive contacts outside of the targeted epitope}

The goal of reverse engineering an $\mathrm{Ab}$ is to scaffold the desired epitope to re-elicit Abs that solely recognize the epitope [6,57]. However, the 4E10 linear epitope, as currently defined, is smaller than typical $\mathrm{Ab} /$ antigen interfaces, which poses the design challenge of isolating humoral responses to the epitope and not contiguous scaffold surfaces. Previous crystal structures of 4E10/ ES complexes showed that many ESs achieved this goal well, including T93 [15,55]. However, GEP/T117 complex structures reported here showed extensive GEP/scaffold contacts (SA for GEP2 contacts to scaffold minus epitope $\left.=308 \AA^{2}\right)($ Fig. 11). A dominant feature of these interactions was the binding of the sidechain of the GEP-specific residue F54H in a deep hydrophobic cleft of the T117 scaffold protein, a putative phosphotransferase from $S$. typhimurium. These additional contacts raise the concern that Abs elicited by T117 immunizations may have off-target (nonEnv) specificities. Nevertheless, the T117 scaffold is highly complementary to $4 \mathrm{E} 10$ (Sc for GEP2/T117 = 0.69), which may help explain the increased affinity of T117 for 4E10 and GEPs, and may be ideal for preferentially targeting GEPs through the
F54H interaction $(\mathrm{F} 54 \mathrm{H}$ is present in the heavy chain gene used by all GEPs). The additional T117 contacts appear to have had the effect of increasing the affinity for T117 over other ESs by two orders of magnitude for $4 \mathrm{E} 10$ and by one to three orders of magnitude for the GEPs. However, structural superpositions show that these extra $\mathrm{Ab} / \mathrm{scaffold}$ interactions do not affect $\mathrm{Ab}$ /epitope interactions, or the structure of the epitope in the complexes, which are highly conserved (Fig. 8B).

GEPs displayed a similar degree of limited polyspecificity to $4 \mathrm{E} 10$, but different autoreactivity

A validated phage-displayed library consisting of 413,611 overlapping 36-mer peptides spanning the entire human proteome combined with phage immunoprecipitation sequencing (PhIP-Seq) was used to assess the polyspecificity and autoantigen recognition profiles of GEPs in comparison to $4 \mathrm{E} 10$ [17,50] (Fig. 12A, Tables 5, 6, and 7). GEP 2 and GEP 4 were selected to represent both the clustering (GEP 2) and 96H mutant (GEP 4) GEPs, and an affinity-matured, murine anti-canine CD28 Ab, 1C6 [58], was included for comparison (Fig. 12A, Table 8). The top hit in the $4 \mathrm{E} 10 \mathrm{Fv}$ PhIP-Seq analysis reported here, a peptide derived from the type 2 inositol 1,4,5-trisphosphate receptor $\left(\mathrm{IP}_{3} \mathrm{R}\right)$, matches the top hit from the previous PhIP-Seq analysis of IgG 4E10 [17]. However, overall scores were considerably reduced in the PhIPSeq analysis of $4 \mathrm{E} 10$ as an Fv construct versus intact IgG (replicate average $-\log _{10} P$-values for the top ten scoring peptides of 35.3 
GEP 1

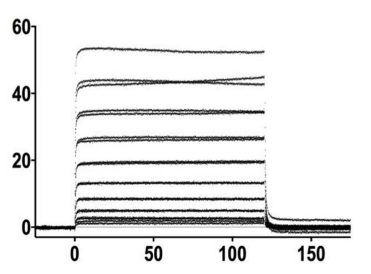

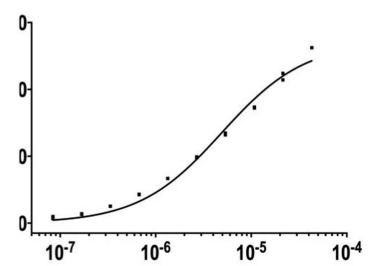

GEP 3
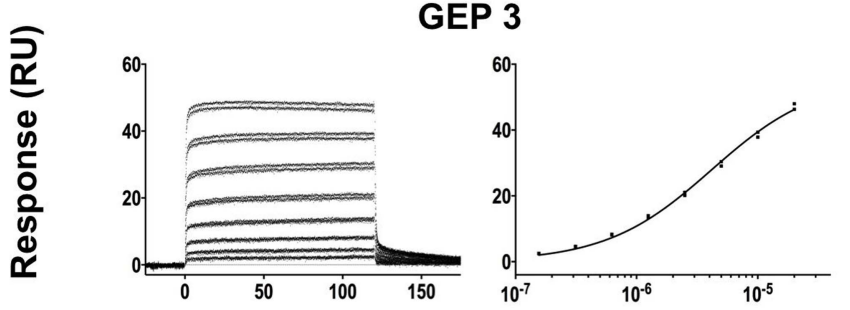

GEP 7

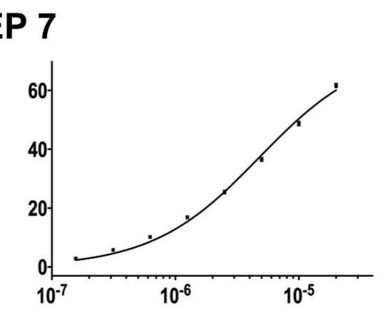

Concentration (M)

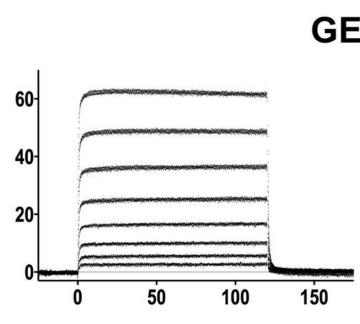

Time (s)

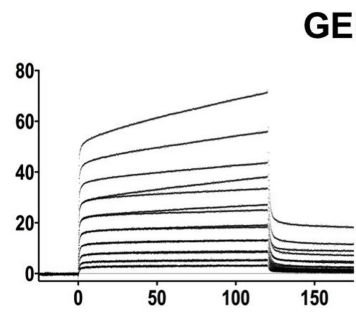

GEP 2

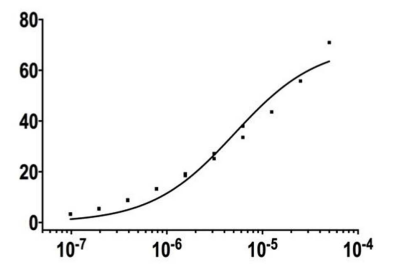

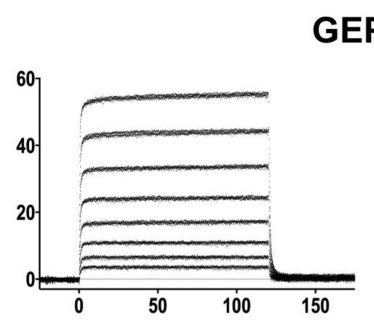

Time (s)
GEP 8

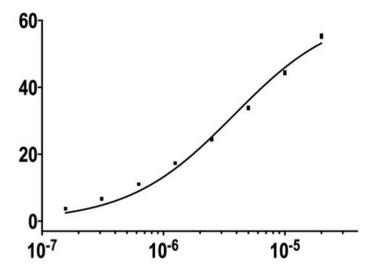

Concentration (M)

Figure 7. SPR sensorgrams of the interactions between ES T344 and the indicated GEPs (left plots) and the analysis of equilibrium responses versus concentration (right plots). Details of the experiments are given in Table 1.

doi:10.1371/journal.ppat.1004403.g007

to 255 for $\mathrm{IgG}$ versus 4.35 to 12.3 for $\mathrm{Fv}$ ), likely due to decreased accessibility of coupled $\mathrm{FV}_{\mathrm{V}}$ relative to $\mathrm{IgG}$, an increased chance of inactivating $\mathrm{Fv}$ versus IgG during chemical coupling, and the inherent increase in local avidity of bivalent $\mathrm{IgG}$ versus univalent $F_{V}$ on potentially sparsely-coupled beads. Given these caveats, overall scoring behavior was very similar across the Fvs tested, with $4 \mathrm{E} 10$ and 1C6, the affinity-matured Abs, showing the highest average scores. GEP 4 and 1C6 showed the largest number of high-scoring hits, with 61 and 194 peptides with replicateaveraged $-\log _{10} P$-values of $\geq 4.0$ respectively; 4 E10 and GEP2 had 12 and 20 peptides, respectively, scoring $\geq 4.0$. Qualitatively, the results were not dramatically different, but with GEP 4 and 1C6 showing nominally greater spreads of top-scoring peptides rising above the bulk responses. None of the top-scoring three-dozen 4E10 peptides appeared in the top three-dozen hits from either GEP; however two of the top-scoring dozen GEP peptides (derived from zinc finger Ran-binding domain-containing protein 3 or hyaluronidase-3 isoform 1 precursor) were in common between GEP 2 and GEP 4, scoring 1 and 12 (GEP 2) and 4 and 2 (GEP 4), respectively. However, no common peptide motifs could be identified within or between $\mathrm{FV}_{\mathrm{V}}$ results. None of the $\mathrm{IP}_{3} \mathrm{R}$ peptides scored in the top 65,000 GEP hits. While 1C6 showed the highest scoring spread of top hits (replicate average $-\log _{10} P$ values for the top ten scoring peptides of 12.14 to 30.9 ), the top ten scoring peptides displayed a considerably higher average hydrophobic character $(\Phi)$, with average $\Phi$ values of: $4 \mathrm{E} 10=0.37$; GEP $2=0.42$; GEP $4=0.45 ; 1 \mathrm{C} 6=0.71$ (higher values are more hydrophobic). Using relative hydrophobicity of the top-scoring PhIP-Seq peptides as a surrogate measure of the overall hydrophobicity of the combining site was consistent with the structures of the Abs (Fig. 12B), where the 1C6 combining site is structured as a large, broad, very hydrophobic concavity and 4E10 and its GEPs sporting smaller, convex hydrophobic surfaces.

\section{Pre-binding of $4 \mathrm{E} 10$ at the MPER affects the binding of} bnAb b12 at the CD4 binding site

In order to test the hypothesis that $4 \mathrm{E} 10$ may induce global conformational changes in gp $140_{3}$ as part of a higher-order neutralization mechanism [17,21], consistent with downstream effects such as gp120 release, binding of Abs to epitopes distant from the MPER (the V3 loop, by 447-52D [59], and the CD4 binding site, by b12 [60]) was assayed by SPR in the presence or absence of saturating 4E10 (Fig. 13). The qualitative results show that $4 \mathrm{E} 10$ pre-binding does not affect $447-52 \mathrm{D}$ binding to the flexible, extended V3 loop, but does alter the association kinetics of b12 at the CD4 binding site, suggesting that 4E10 binding induced global conformational changes in gp $140_{3}$ registering at distant sites. Since b12 dissociation kinetics were unaffected, 4E10 did not preclude achieving a similar b12 bound-state conformation.

\section{Discussion}

Reverse engineered ESs are ideal reagents for studying the binding properties of GEPs. Where peptides and Env do not 


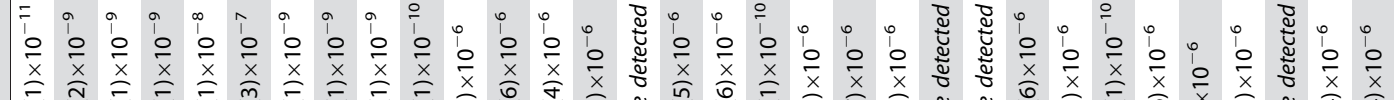
资

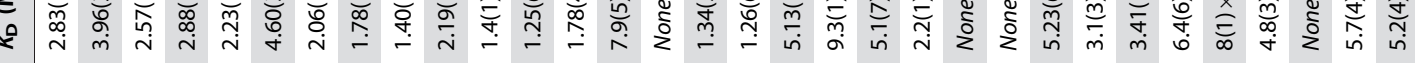

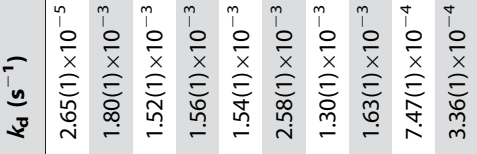

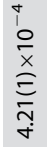

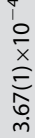

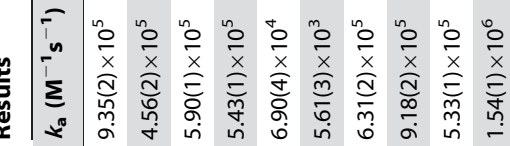

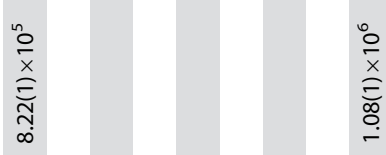

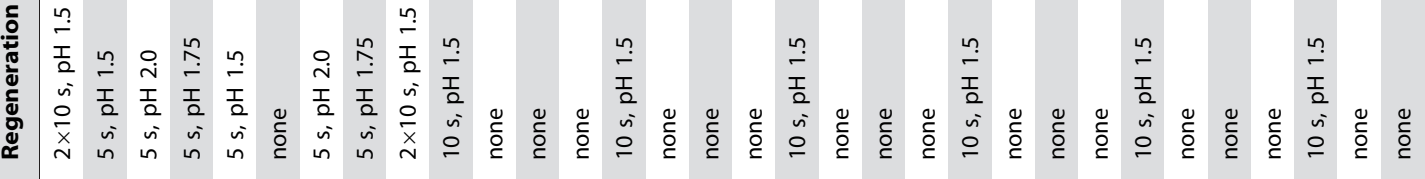

온

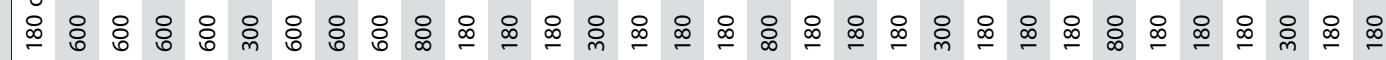

厸

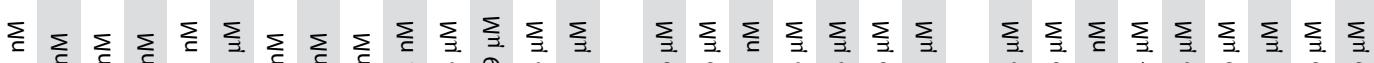

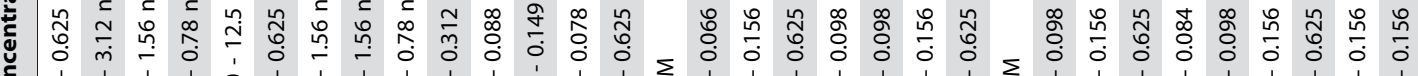

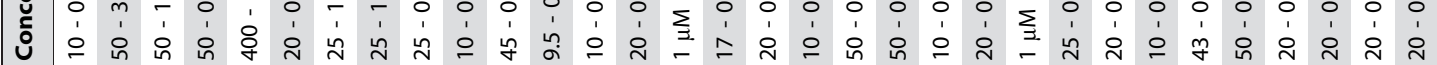

○一 产焉

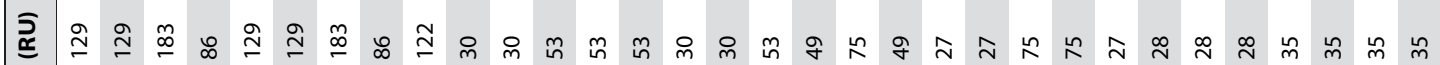




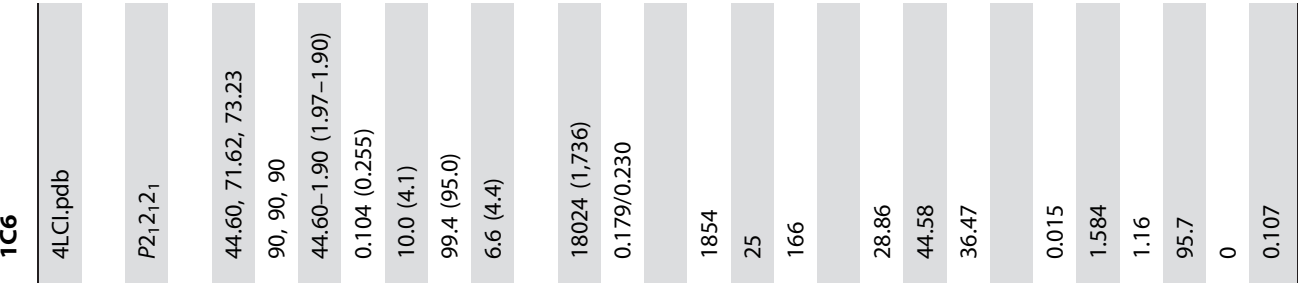

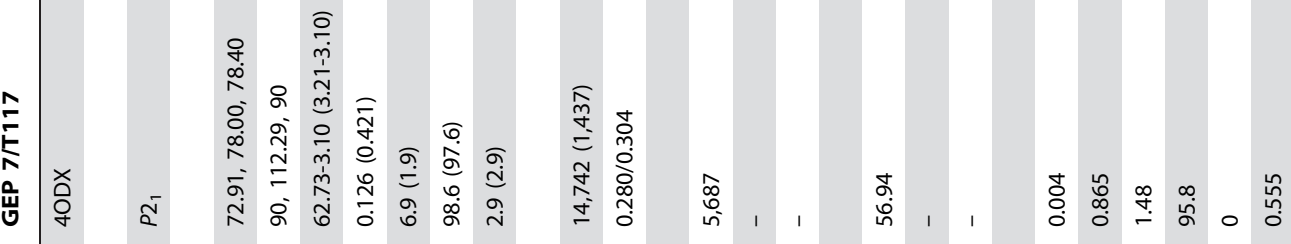

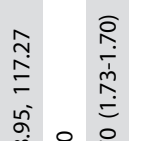

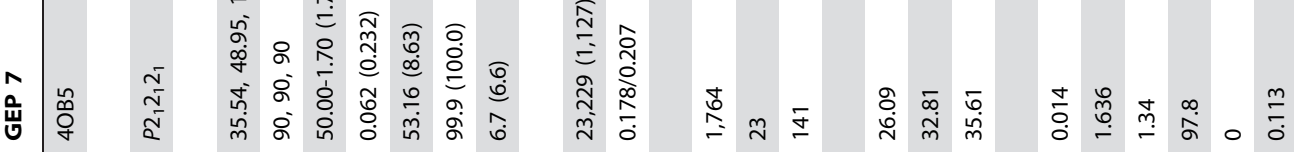

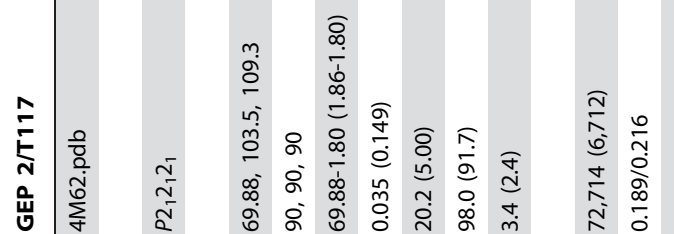

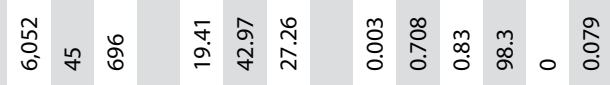

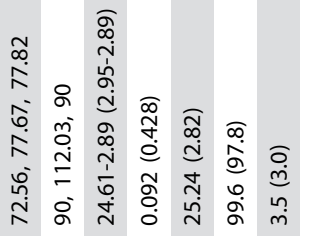

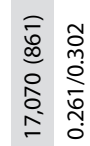

ڤั
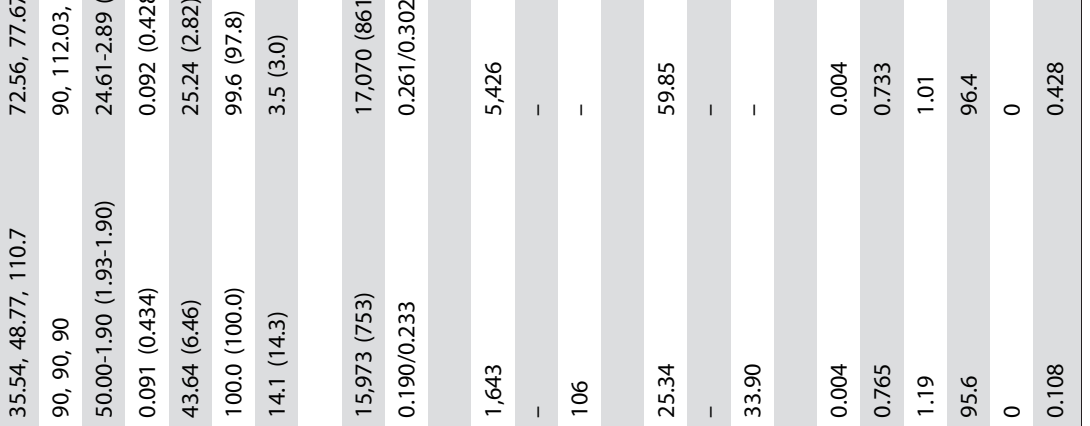

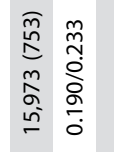

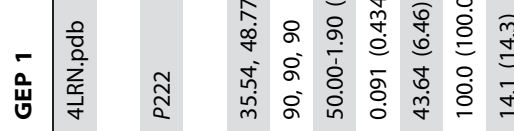

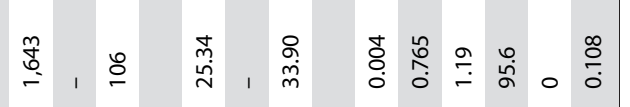

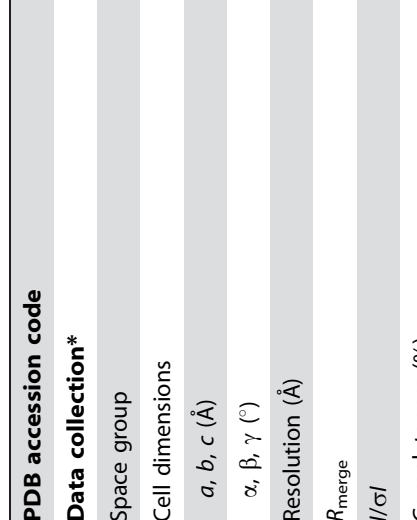



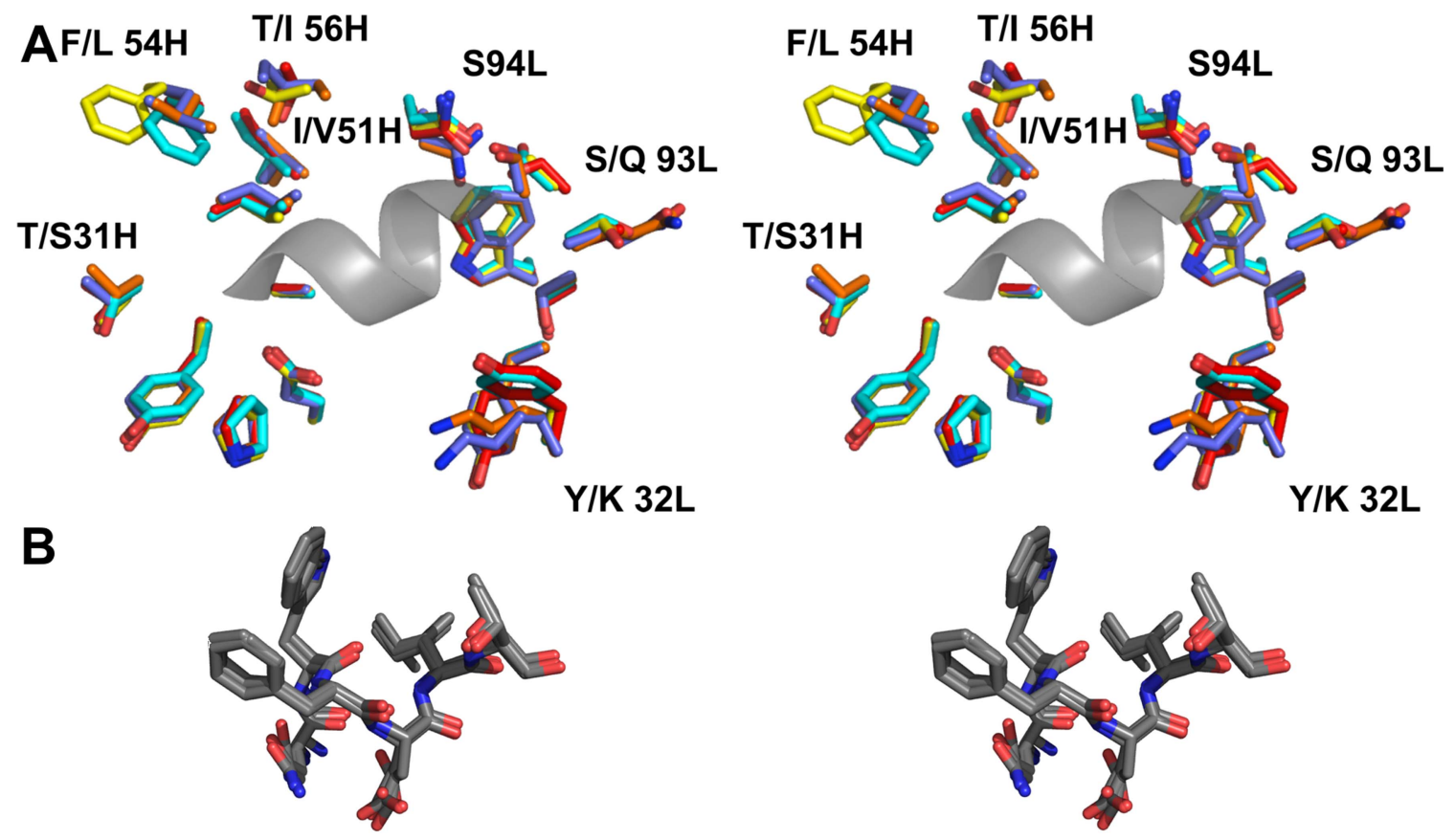

Figure 8. The epitope binding site is conserved between $4 E 10$ and its GEPs. (A) Residues from the combining sites of $4 E 10$ and GEPs, superimposed based on bound-state structures, contacting the NWFDIT core epitope (shown in a cartoon representation as a grey corkscrew) are shown in a stereo view. 4E10 and GEP residues are shown in licorice stick representation and colored as follows: 4E10 Fv (3LH2.pdb, in complex with ES T88) in purple, 4E10 Fab (2FX7.pdb, in complex with an extended 16-mer NWFDIT-containing peptide) in orange, GEP 1 in yellow, GEP 2 in cyan, and GEP 7 in red. Analyses and depictions were restricted to the core epitope to maximize comparability. Calculated SA buried in the complexes and Sc between core epitope and $A b$ are: $4 \mathrm{E} 10 \mathrm{Fab} / \mathrm{epitope}$ peptide: $\mathrm{SA}=355 \AA^{2}, \mathrm{SC}=0.78 ; 4 \mathrm{E} 10 / \mathrm{T} 88: \mathrm{SA}=367 \AA^{2}, \mathrm{SC}=0.77 ; \mathrm{GEP} 1 / \mathrm{T} 117: \mathrm{SA}=342 \AA^{2}$, $\mathrm{SC}=0.69$; GEP 2/T117: $\mathrm{SA}=305 \AA^{2}, \mathrm{Sc}=0.74$; GEP 7/T117: $\mathrm{SA}=343 \AA^{2}, \mathrm{Sc}=0.66$. (B) The NWFDIT core epitope is shown in a licorice stick representation isolated from the superimposed complex structures, highlighting the high degree of conservation of both the position and conformation of the peptide across 4E10 and GEP complexes.

doi:10.1371/journal.ppat.1004403.g008

display sufficient affinities, the best ESs display strong affinities across the GEP ensemble, allowing for the biophysical characterization of 4E10 ontogeny by using ESs to compare 4E10 and GEP binding kinetics and bound-state crystal structures. Consistent with current theory and previous results comparing GEPs with matured bnAbs or other Abs, 4E10 displays orders-of-magnitude better affinities than candidate GEPs for both Env gp $140_{3}$ proteins and engineered ESs. This gain in affinity is potentially sufficient to account for the concurrent gain in neutralization potency over GEPs. Previous results showing minimal contributions from FWR mutations [61] and comparisons of complex structures of $4 \mathrm{E} 10$ with GEP/T117 complex structures, which showed near-complete conservation of the recognition interface (Fig. 8), argue that affinity maturation was likely due, at least in part, to the small number of somatic mutations in the CDR regions, e.g. 32L and $95 \mathrm{H}$, that add or improve direct contacts to epitope. This limited number of mutations is presumably readily achievable during conventional vaccination. Based on PhIP-Seq peptidome binding results (Fig. 12A), 4E10 and GEPs have distinct autoantigen profiles, suggesting that $4 \mathrm{E} 10$ autoreactivity was acquired during ontogeny and not inherent in GEPs, consistent with recognizable GEPs populating naïve repertoires of mature B cells at relatively high frequencies [16]. Among ESs, T117 in particular interacts with GEPs sufficiently strongly to drive B cell activation and maturation (Fig. 2D) and selectively interacts with GEP-specific structural features, e.g. F54H (Fig. 11). These aspects of 4E10 combine to seemingly argue that 4E10 ontogeny follows a relatively short path and that directed re-elicitation of $4 \mathrm{E} 10$, and perhaps other bnAbs, may be an achievable goal.
In many aspects, however, 4E10 ontogeny appears more convoluted. Contrasting with the consensus model of Ab ontogeny and results from other systems [38], 4E10 is considerably less thermostable than GEPs, which was difficult to account for only from static views of structures. This lowers the headroom available to tolerate mutations that increase affinity or potency that otherwise might degrade stability, potentially adding a significant hurdle to re-elicitation of $4 \mathrm{E} 10$, but clearly does not limit the ability of $4 \mathrm{E} 10$ to bind to or neutralize HIV. The conformer ensemble sampled by GEP combining sites echoes the startling plasticity of $4 \mathrm{E} 10$, with structural comparisons of bound versus unbound states (Figs. 9 and 10) showing perhaps a small degree of $4 \mathrm{E} 10$ LCDR rigidification, but an increase in the conformer ensemble sampled by the HCDRs. This directly contradicts the consensus model, and specific examples [40], of Ab maturation, showing alternatively that preconfiguration of $4 \mathrm{E} 10$ does not occur during, or contribute to, affinity maturation. HCDR flexibility is highlighted by $\mathrm{F} 29 \mathrm{H}$, which is able to flip out into solvent in the unbound 4E10 and GEP 1 structures, allowing HCDR 1 to dynamically sample multiple conformers. A high number of conserved glycine residues may contribute to $4 \mathrm{E} 10$ and GEP HCDR mobility. The reduced affinities due to decreased $k_{\mathrm{a}} \mathrm{s}$ (Fig. 2D), relative to the clustering GEPs, of GEP 4 and 6 with non-glycine residues at position $96 \mathrm{H}$, predicted to restrict HCDR3 conformer sampling, suggests that HCDR3 mobility was needed to achieve the bound-state conformation with optimal kinetics by destabilizing non-optimal conformers. Retention of significant combining site plasticity also strongly argues for a functional role other than polyspecificity, which is unremarkable in comparison to 
Table 3. Epitope contacts for $4 \mathrm{E} 10$ and GEPs determined from complex crystal structures; electrostatic contacts are bolded; otherwise, the contacts are mediated by van der Waals interactions.

\begin{tabular}{|c|c|c|c|c|c|}
\hline NWFDIT epitope & 4E10 Fab (16-mer peptide) & 4E10 Fv (T88) & GEP 1 (T117) & GEP 2 (T117) & GEP 7 (T117) \\
\hline \multirow[t]{8}{*}{ Asn } & - & - & L 32 TYR & L 32 TYR & L 32 TYR \\
\hline & L 91 TYR & - & L 91 TYR & L 91 TYR & L 91 TYR \\
\hline & L 91 TYR & - & L 91 TYR & L 91 TYR & L 91 TYR \\
\hline & L 92 GLY & L $92 \mathrm{GLY}$ & L 92 GLY & L 92 GLY & L 92 GLY \\
\hline & L 92 GLY & L 93 GLN* & L 92 GLY & L 92 GLY & L 92 GLY \\
\hline & L $93 \mathrm{GLN}^{*}$ & L 94 SER & L 93 SER* & L 93 SER* & L 93 SER* \\
\hline & L 94 SER & L 94 SER & - & - & - \\
\hline & L 94 SER & & - & - & - \\
\hline \multirow[t]{10}{*}{ Trp } & H 33 ALA & H 33 ALA & H 33 ALA & H 33 ALA & H 33 ALA \\
\hline & H $50 \mathrm{GLY}$ & H $50 \mathrm{GLY}$ & H 50 GLY & H $50 \mathrm{GLY}$ & H $50 \mathrm{GLY}$ \\
\hline & H $51 \mathrm{VAL}^{*}$ & H $51 \mathrm{VAL}^{*}$ & H 51 ILE* & H 51 ILE* $^{*}$ & H 51 ILE* \\
\hline & H 52 ILE & H 52 ILE & H 52 ILE & H 52 ILE & H 52 ILE \\
\hline & H 56 ILE* & - & H 56 THR & - & - \\
\hline & H 56 ILE* & H 56 ILE* & H 56 THR $^{*}$ & - & H 56 THR $^{*}$ \\
\hline & - & H 58 ASN & - & - & - \\
\hline & H 58 ASN & H 58 ASN & H 58 ASN & H 58 ASN & H 58 ASN \\
\hline & L 94 SER & L 94 SER & - & - & - \\
\hline & L 94 SER & L 94 SER & - & - & - \\
\hline \multirow[t]{6}{*}{ Phe } & H 47 TRP & H 47 TRP & H 47 TRP & H 47 TRP & H 47 TRP \\
\hline & H 100J PHE & H 100J PHE & H 100J PHE & H 100J PHE & H 100J PHE \\
\hline & L 91 TYR & L 91 TYR & L 91 TYR & L 91 TYR & L 91 TYR \\
\hline & L 93 GLN* & L 93 GLN* & L 93 SER* & L 93 SER* & L 93 SER* \\
\hline & L 94 SER & L 94 SER & L 94 SER & L 94 SER & L 94 SER \\
\hline & L 96 SER & L 96 SER & L 96 SER & L 96 SER & L 96 SER \\
\hline \multirow[t]{2}{*}{ Asp } & L 32 LYS* & L 32 LYS* & L 32 TYR* & L 32 TYR* & L 32 TYR* \\
\hline & L 32 LYS* & L 32 LYS* & L 32 TYR* $^{*}$ & L 32 TYR* & L 32 TYR* $^{*}$ \\
\hline \multirow[t]{3}{*}{ lle } & H 52 ILE & H 52 ILE & H 52 ILE & H 52 ILE & H 52 ILE \\
\hline & H 54 LEU* & H 54 LEU* & H 54 PHE* $^{*}$ & H 54 PHE* $^{*}$ & H 54 PHE* \\
\hline & H 56 ILE* $^{*}$ & H 56 ILE* & H 56 THR $^{*}$ & - & H 56 THR $^{*}$ \\
\hline \multirow[t]{7}{*}{ Thr } & H 31 THR $^{*}$ & H $31 \mathrm{THR}^{*}$ & $\mathrm{H} 31 \mathrm{SER}^{*}$ & H 31 SER* & H 31 SER $^{*}$ \\
\hline & H 32 TYR & H 32 TYR & H 32 TYR & H 32 TYR & H 32 TYR \\
\hline & H 33 ALA & H 33 ALA & H 33 ALA & H 33 ALA & H 33 ALA \\
\hline & H 52 ILE & H 52 ILE & H 52 ILE & H 52 ILE & H 52 ILE \\
\hline & H 95 GLU & H 95 GLU & H 95 GLU & H 95 GLU & H 95 GLU \\
\hline & H 95 GLU & H 95 GLU & H 95 GLU & H 95 GLU & H 95 GLU \\
\hline & H 100F PRO & H 100F PRO & H 100F PRO & H 100F PRO & H 100F PRO \\
\hline
\end{tabular}

Asterisks indicate residues that differ between GEPs and 4E10.

doi:10.1371/journal.ppat.1004403.t003

other Abs, based on PhIP-Seq peptidome binding results (Fig. 12A). Minimal focusing of apparent polyspecificity also contradicts the consensus model, and specific examples [62], of maturation. Also unexpectedly, the $\sim 100$-fold increase in affinity of $4 \mathrm{E} 10$ over GEPs to T117 is through a decreased $k_{\mathrm{d}}($ Fig. $2 \mathbf{D})$, suggesting that improvements in binding affinity arose from a more favorable bound state and not a decrease in entropic barriers imposed by more plastic GEPs. Thermodynamic studies of $4 \mathrm{E} 10$ and GEPs were not possible because no single antigen, needed for valid comparisons, bound to both $4 \mathrm{E} 10$ and GEPs with parameters accessible to measurement. However, while crystal structures showed a highly-conserved bound state in both $4 \mathrm{E} 10$ and GEPs, the small number of improved contacts could not account fully for the observed improvement in affinity. Complicating this analysis, and its use as a vaccine immunogen, are the extensive contacts between GEPs, and presumably also 4E10, and the scaffold of T117 outside of the stabilized MPER epitope (Fig. 11). The interaction with $\mathrm{T} 117$ also highlights another possibility. The 4E10 combining site extends beyond the minimal, linear epitope in T117, making contacts to the scaffold. Unless the MPER epitope forms an isolated structure extended away from the rest of Env, 4E10 may make contacts to elements of Env outside of the linear 4E10 epitope, as it does with T117. HCDR conformer dynamics may therefore be understood as enabling 
Table 4. Additional contacts between GEPs and the scaffold moiety of ES T117 outside of the grafted 4E10 epitope.

\begin{tabular}{|c|c|c|c|}
\hline Epitope-scaffold T117 & GEP 1 & GEP 2 & GEP 7 \\
\hline 8 ALA & H 100E LYS & H 100E LYS & H 100E LYS \\
\hline \multirow[t]{4}{*}{56 ARG } & H 54 PHE & H 54 PHE & H 54 PHE \\
\hline & H 55 GLY & H 55 GLY & H 55 GLY \\
\hline & - & H 56 THR & H 56 THR \\
\hline & - & H 56 THR & H 56 THR \\
\hline \multirow[t]{3}{*}{60 PHE } & H 54 PHE & H 54 PHE & H 54 PHE \\
\hline & H 55 GLY & H 55 GLY & H 55 GLY \\
\hline & - & H 56 THR & - \\
\hline 62 THR & H 54 PHE & H 54 PHE & H 54 PHE \\
\hline 64 LEU & H 53 ILE & H 53 ILE & H 53 ILE \\
\hline $73 \mathrm{ILE}$ & H 54 PHE & H 54 PHE & H 54 PHE \\
\hline 75 HIS & H 54 PHE & H 54 PHE & H 54 PHE \\
\hline \multirow[t]{3}{*}{100 ALA } & H 53 ILE & H 53 ILE & H 53 ILE \\
\hline & H 54 PHE & H 54 PHE & H 54 PHE \\
\hline & A 73 LYS & H 73 LYS & H 73 LYS \\
\hline $101 \mathrm{GLY}$ & H 73 LYS & H 73 LYS & H 73 LYS \\
\hline \multirow[t]{2}{*}{$125 \mathrm{ASN}$} & H 100F PRO & H 100F PRO & H 100F PRO \\
\hline & H 100E LYS & H 100E LYS & H 100E LYS \\
\hline \multirow[t]{2}{*}{127 LEU } & H 53 ILE & H 53 ILE & H 53 ILE \\
\hline & H 54 PHE & H 54 PHE & H 54 PHE \\
\hline \multirow[t]{5}{*}{128 TRP } & - & H 100C LEU & - \\
\hline & - & H 100C LEU & - \\
\hline & H 100D GLY & H 100D GLY & H 100D GLY \\
\hline & H 100E LYS & H 100E LYS & H 100E LYS \\
\hline & H 100F PRO & H 100F PRO & H 100F PRO \\
\hline
\end{tabular}

doi:10.1371/journal.ppat.1004403.t004

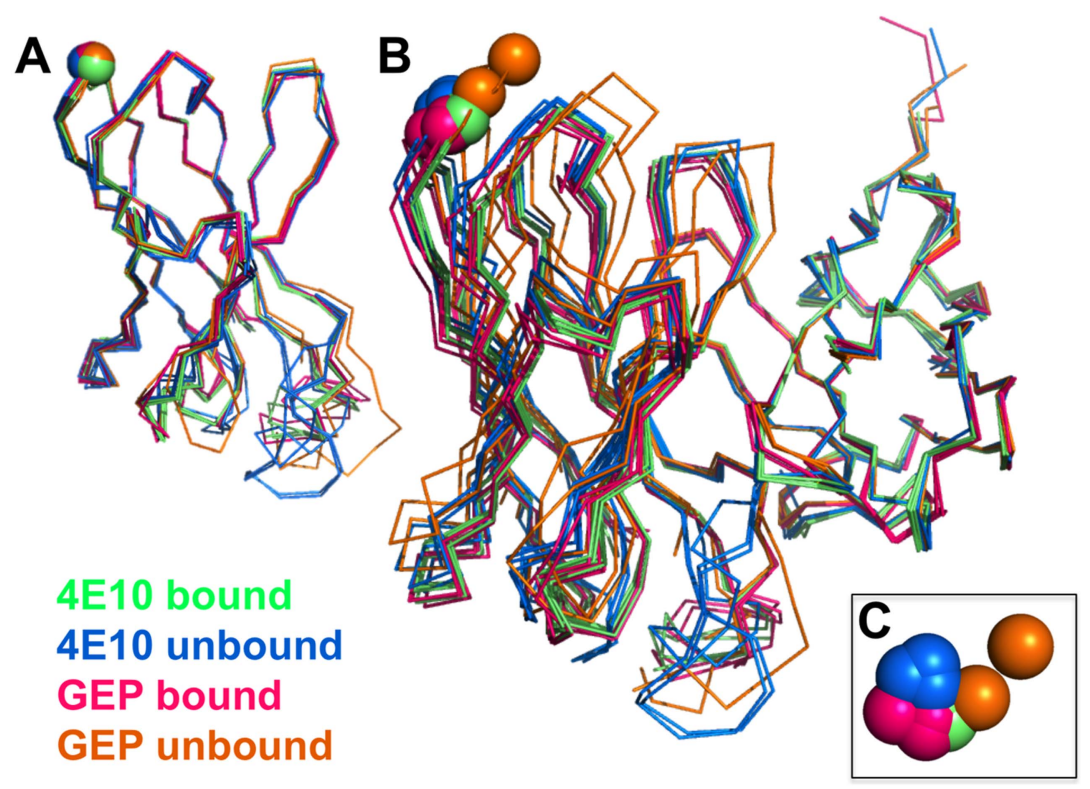

Figure 9. Interdomain movements within Fv cassettes are limited. (A) Superpositions of the $V_{H}$ domains from two $4 E 10$ ligand-bound structures (2FX7.pdb, 3LH2.pdb), unbound 4E10 (4LLV.pdb), ligand-bound GEP 1 (4M8Q.pdb), unbound GEP 1 (4LRN.pdb), ligand-bound GEP 2 (4M62.pdb), ligandbound GEP 7 (4ODX.pdb), and unbound GEP 7 (4OB5.pdb) are shown in $\mathrm{C} \alpha$ backbone representations, colored as indicated. Residue P14H in each Fv, chosen as a reference point to illustrate interdomain movement upon binding between 4E10 and GEPs, is shown as a sphere and colored to match the corresponding backbone. When isolated $\mathrm{V}_{\mathrm{H}}$ domains are superimposed, the $\mathrm{P} 14 \mathrm{H}$ spheres are nearly coincident, indicating that the $\mathrm{V}_{\mathrm{H}}$ domain structure is highly conserved among these Abs. (B) FV cassettes of $4 \mathrm{E} 10$ and GEPs, colored as in (A), superimposed only on $V_{L}$ domains (oriented on the right side of the panel), are shown as represented in $(\mathbf{A})$. In this view, interdomain movements can be visualized as the relative movement of $V_{H}$ domains, particularly at the P14H reference point. (C) Orthogonal view of the P14H spheres excerpted from (B) illustrating the pattern and degree of interdomain movements. doi:10.1371/journal.ppat.1004403.g009 

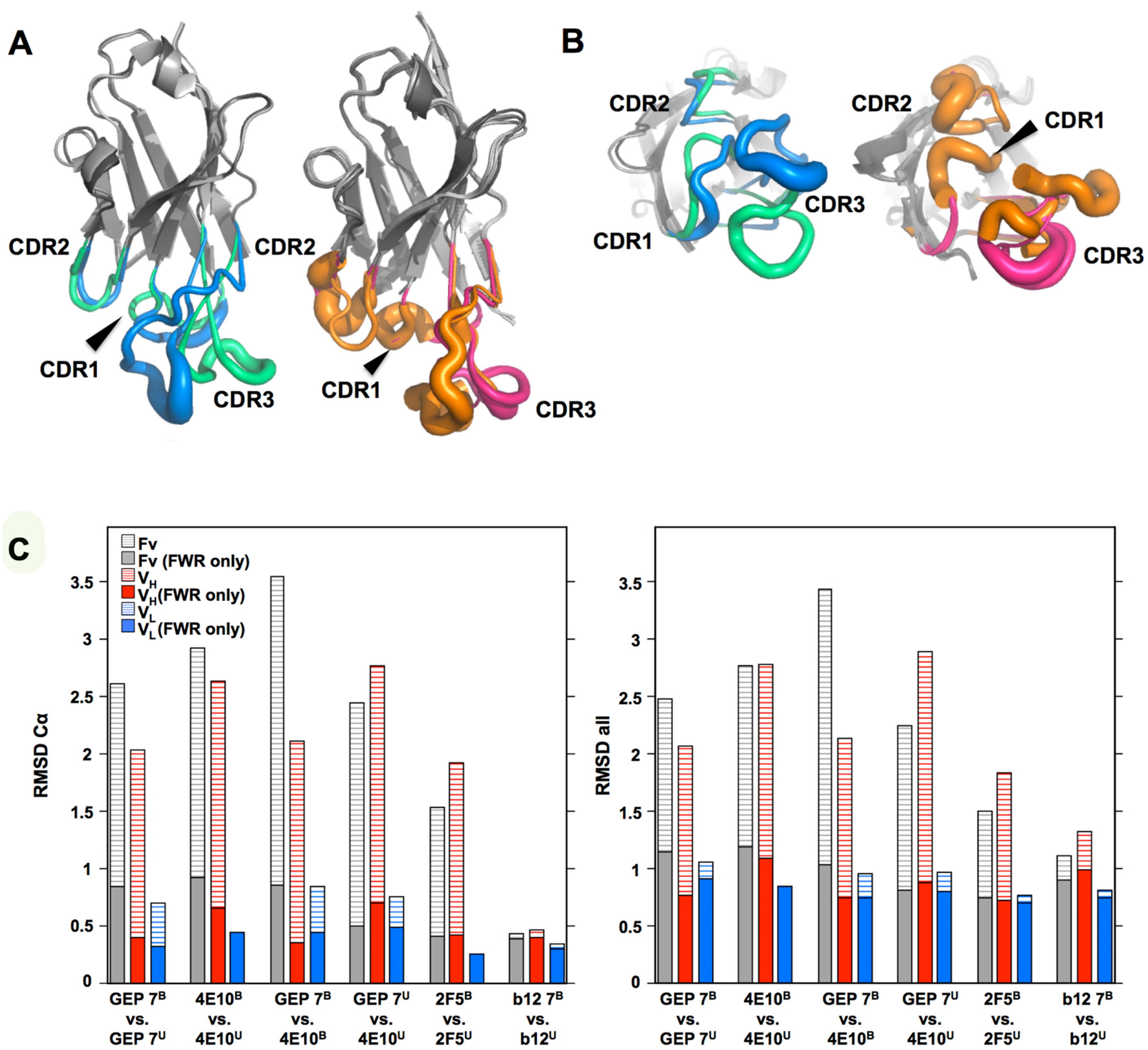

Figure 10. CDR restructuring. Views from the side (A) and below (B) are shown of superpositions of isolated $V_{H}$ domains, in cartoon representations, with FRW regions colored grey and $\beta$-strands indicated as arrows. HCDRs are shown in a B-factor putty representation (tube width correlates with crystallographic Debye-Waller, or $B$, factor), colored by Ab. On the left in both frames is shown the superposition of $\mathrm{V}_{\mathrm{H}}$ domains from ligand-bound 4E10 (3LH2.pdb, with green HCDRs) vs. unbound 4E10 (4LLV.pdb, with blue HCDRs), and on the right in both frames is shown the superposition of ligand-bound structures of GEP 1 (4M8Q.pdb), GEP 2 (4M62.pdb), and GEP 7 (4ODX.pdb), all with pink HCDRs, vs. unbound GEP 1 (4LRN.pdb) and GEP 7 (4OB5.pdb), both with orange HCDRs. (C) RMSD values for $\mathrm{V}_{\mathrm{H}}, \mathrm{V}_{\mathrm{L}}$, or Fv superpositions, calculated with or without CDR residues, are plotted for $\mathrm{C} \alpha$ atoms only (left) or all atoms (right).

doi:10.1371/journal.ppat.1004403.g010

such interactions, which may foster conformational changes in Env leading to neutralization by any of several mechanisms. Prebinding of $4 \mathrm{E} 10$ to gp $140_{3}$ affected b12 binding at the CD4 site distant from the MPER (Fig. 13), indirectly demonstrating a global conformational change consistent with this supposition. Additional interactions between GEPs and the scaffold moiety of T117 would also be predicted to drive rigidification of an even greater portion of the combining site during conventional immunization, increasing the distinction between $4 \mathrm{E} 10$ and a matured Ab derived from a 4E10 GEP stimulated with T117.

T117 was the product of a cutting-edge design effort to generate a structurally-stabilized MPER epitope with optimized binding properties for use as a vaccine immunogen to drive $4 \mathrm{E} 10$ ontogeny based on the current paradigm of affinity maturation. However, 4E10 appears to take the affinity maturation pathway less traveled, one that contrasts, in many fundamental ways, the current paradigm. This raises the concern that conventional immunization protocols, based on the current paradigm of structural stabilization of optimal binding conformers, will not successfully re-elicit $4 \mathrm{E} 10$ or other unconventional Abs. Understanding unconventional maturation pathways then becomes paramount for the future of molecular vaccinology, allowing efforts to focus on re-eliciting Abs identified as the products of conventional ontogeny in the near term while developing 

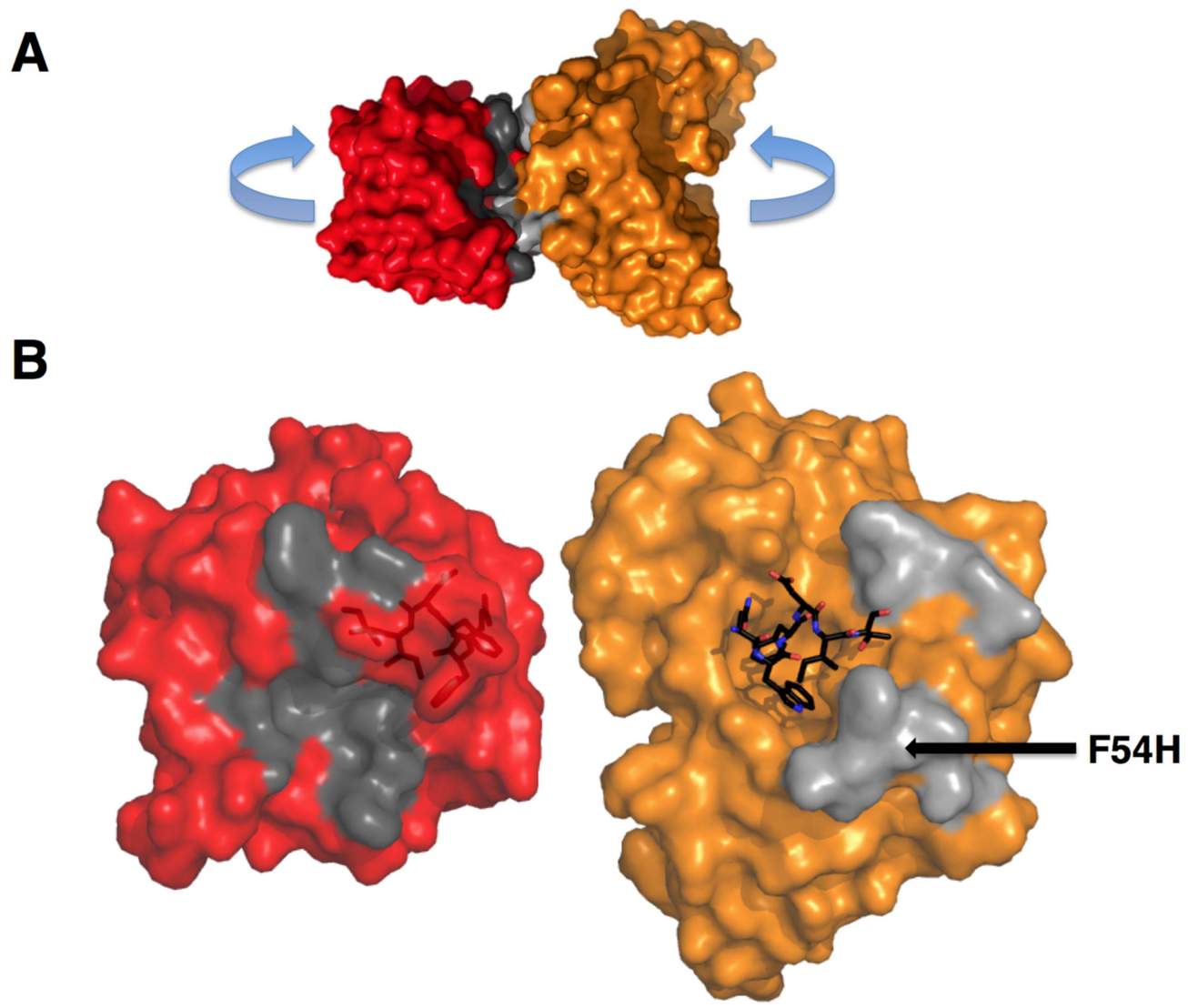

Figure 11. GEPs binding surfaces on T117. (A) The complex of GEP 2 (orange) bound to ES T117 (red) is shown in molecular surface representations. Non-epitope scaffold contacts are highlighted in grey. (B) The interaction partners were separated as indicated in (A) to reveal details of the interface. T117, on the left, is shown in a red semi-transparent molecular surface representation with the NWFDIT epitope, in a licoricestick representation, visible within the surface. The GEP 2 Fv structure is shown on the right, colored as in (A). The NWFDIT epitope, excised from the T117 structure, is shown as bound for reference. The footprint of GEP 2 (non-epitope contacts) on T117 is colored dark grey; the footprint of T117 to non-epitope residues on GEP 2 is colored light grey. The position of the side-chain of F54H is indicated. doi:10.1371/journal.ppat.1004403.g011

unconventional vaccination strategies to target exceptional Abs in the long term.

\section{Materials and Methods}

\section{Protein prediction, expression, purification and characterization}

The 4E10 heavy and light chain nucleotide sequences were analyzed using JoinSolver [63], IMGT/V-QUEST [64,65], AbOrigin [66], SoDA [67] and iHMMune [68] to compositely identify segments with the fewest nucleotide mismatches, generating a combinatorial ensemble of 12 GEPs (Fig. 1). Each derived GEP candidate consisted of a single $\mathrm{V}_{\mathrm{L}}$ domain sequence assigned with high confidence (IGKV3-20*01 plus IGKJ1*01), one $\mathrm{V}_{\mathrm{H}}$ gene segment also confidently assigned (IGHV1-69*06), plus one of six likely D segments (IGHD1-1*01, IGHD6-19*01, IGHD7$27 * 01$, IGHD6-25*01, IGHD1-26*01, IGHD4-17*01) and either of two likely J segments (IGHJ4*02, IGHJ1*01). The CDR3 junctions and presumed N-nucleotide insertions in mature 4E10 were retained in the candidate GEPs. Sequences are numbered following Kabat [24]. 4E10, eight of the 12 GEPs, and 1C6 Fvs were engineered, expressed as inclusion bodies in $E$. coli BL21(DE3) RIL cells (Invitrogen), refolded, purified, and validated by SEG and PAGE as previously described [18]. Circular dichroism (CD) spectra of 4E10 Fv and GEPs were measured on a J-815 spectrometer (Jasco) at a concentration of $10 \mu \mathrm{M}$ in $10 \mathrm{mM} \mathrm{Na} 2 \mathrm{HPO}_{4} / \mathrm{KH}_{2} \mathrm{PO}_{4}(\mathrm{pH}=7.4)$. Temperature melts were performed at $210 \mathrm{nM}$ with a temperature ramp from $25^{\circ} \mathrm{C}$ to $95^{\circ} \mathrm{C}$ at a slope of $2^{\circ} \mathrm{C} /$ minute, data pitch of $2^{\circ} \mathrm{C}$, and delay time of $10 \mathrm{~s}$ (Fig. 2). $\mathrm{T}_{\mathrm{m}} \mathrm{s}$ were determined by nonlinear least-squares analysis using a linear extrapolation model with Spectra Analysis software (Jasco). Fabs of 447-52D and 4E10 were prepared by digestion of IgG with papain (Pierce), affinity chromatography with protein A (Pierce) and preparative SEC (Superdex 200 16/10 column; GE Healthcare); IgG 4E10 was purchased from Polymun Scientific, and IgG 447-52D and Fab b12 were kindly provided by Pamela Bjorkman (Caltech).

\section{Neutralization assays}

Neutralization assays (Fig. 2B) were performed using singleround entry-competent viruses and TZM-bl cells as previously described [53]. Percent neutralization at concentrations of $0.96 \mu \mathrm{M}(4 \mathrm{E} 10$ and GEP Fvs) or $0.17 \mu \mathrm{M}(4 \mathrm{E} 10 \mathrm{IgG})$ was calculated as previously described [18,53].

\section{SPR interaction analyses}

All SPR experiments were performed at $25^{\circ} \mathrm{C}$ on a Biacore T100 instrument with the T200 sensitivity enhancement (GE Healthcare). For analyses of the binding of $4 \mathrm{E} 10$ and GEP FV analytes to chip-captured ES ligands (Fig. 2D, Table 1), ESs at 
A

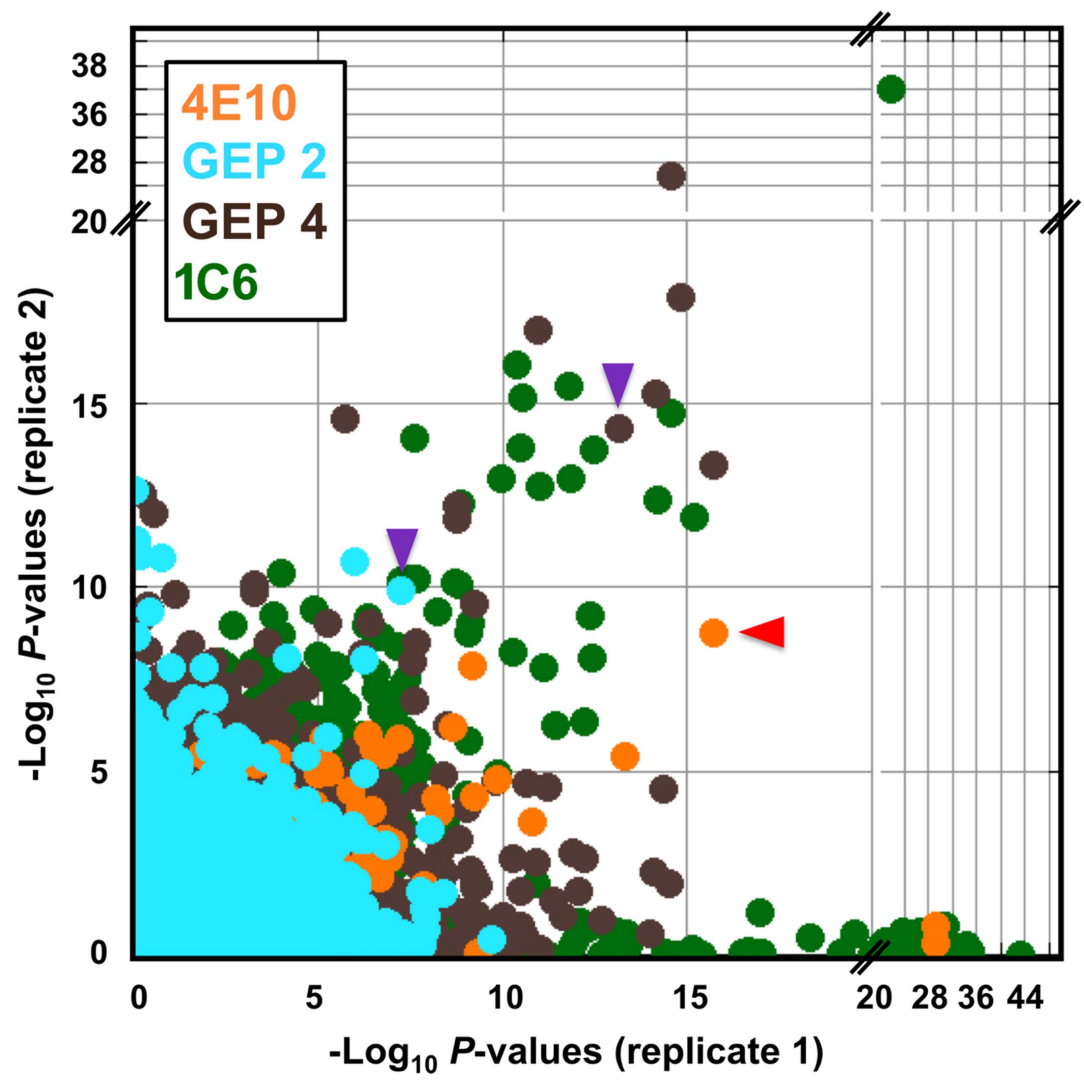

B

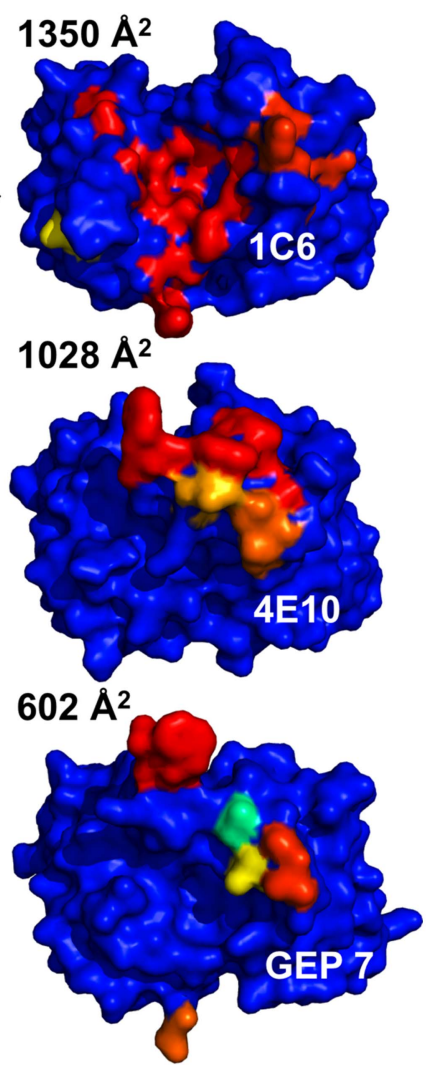

Figure 12. Peptidome binding results. (A) PhIP-Seq results are plotted as $-\log _{10} P$-values, one replicate on the abscissa, the other on the ordinate, colored by $\mathrm{Ab}$ as indicated; note the discontinuity in axis scales. The top scoring $4 \mathrm{E} 10$ peptide derived from $\mathrm{IP}_{3} \mathrm{R}$ is highlighted with a red arrow; one peptide, derived from the zinc finger Ran-binding domain-containing protein 3, which bound to both GEP 2 and GEP 4, is highlighted with purple arrows. Proximity to the diagonal indicates good replicate concordance; peptides with highly discordant replicate values, falling along the axes, were discarded from the analysis. Overall library scoring statistics are: 4E10, average $=0.32, \sigma=0.35$; GEP 2, average $=0.22$, $\sigma=0.44$; GEP 4, average $=0.25, \sigma=0.52 ; 1 \mathrm{C} 6$, average $=0.27, \sigma=0.50$. (B) The molecular surfaces of the Fv domains of 1C6 (4LCl.pdb), unbound 4E10 (4LLV.pdb) and unbound GEP 7 (4OB5.pdb) are shown, oriented with $\mathrm{V}_{\mathrm{H}}$ domains at left and the $\mathrm{V}_{\mathrm{L}}$ domains at right. The surface is colored to show hydrophobic patches, defined by the program HotPatch [80]; patches are colored in descending order of total area (red, orange, yellow, ...). The total surface area for red and orange hydrophobic patches is shown. The crystal structure of GEP 7 is partially disordered in HCDR1 and 3 and so patch area is underrepresented in the calculation.

doi:10.1371/journal.ppat.1004403.g012

$\sim 1 \mu \mathrm{g} / \mathrm{mL}$ were captured on a SA sensor chip (GE Healthcare) following either carboxy (T117) or amine (T72, T93, T344) biotinylation, following the manufacturer's recommended protocol (EZ-Link, Thermo Scientific), in a running buffer of HBS-EP+ (10 mM HEPES, pH 7.4, $150 \mathrm{mM} \mathrm{NaCl,} 3 \mathrm{mM}$ EDTA, $0.05 \%$ P-20; GE Healthcare) plus $0.1 \mathrm{mg} / \mathrm{mL}$ bovine serum albumin. A reference flow cell was left blank. Duplicate 4E10 and GEP FV analyte injections were randomized and run at a flow rate of $50 \mu \mathrm{L} /$ minute. Regeneration, if needed, was achieved by injection of $10 \mathrm{mM}$ glycine at $50 \mu \mathrm{L} /$ minute followed by buffer stabilization. Sensorgrams obtained from SPR measurements were doublereference subtracted [69] with BIAevaluation 2.0.3 software (GE Healthcare) employing previously described methodology [18]; data were fit with either 1:1 or steady-state binding models. For analyses of the binding of $4 \mathrm{E} 10$ and GEP Fv analytes to gp $140_{3}$ (Fig. 2C), gpl $140_{3}$ at $30 \mu \mathrm{g} / \mathrm{mL}$ in $10 \mathrm{mM}$ sodium acetate $(\mathrm{pH}=5.0)$ were direct amine coupled at a density of $\sim 2200$ RUs on a GM5 sensor chip (GE Healthcare); a reference surface was prepared by activating and deactivating a flow cell without the addition of protein; gp $140_{3}$ were prepared as previously described [18]. Duplicate 5 minute, $300 \mathrm{nM}$ injections of $4 \mathrm{E} 10$ and GEP Fv were made in HBS-EP+ at $50 \mu \mathrm{L} /$ minute followed by 5 minutes of dissociation, regeneration with $10 \mathrm{mM}$ glycine $(\mathrm{pH}=1.5)$ for 5 seconds and then 6 minutes of stabilization. Assays of Fab b12 or Fab 447-52D binding to SF162 gp140 3 in the presence or absence of $4 \mathrm{E} 10 \mathrm{Fv}$ (Fig. 13) were conducted in HBS-EP+ buffer. Using standard amine coupling chemistry, 1273 RUs of SF162 gp $140_{3}$ were coupled to a CM5 sensor chip. A reference surface was prepared by activating and deactivating a flow cell without the addition of protein. Two samples were injected at a flow rate of $50 \mu \mathrm{L} /$ minute using the dual injection command in the T100 control software (v2.0.3, GE Healthcare) with injection 1 at 5 minutes, injection 2 at 2 minutes and a final dissociation time of 5 minutes. Fab-alone curves were generated by injecting HBS$\mathrm{EP}+$ followed by an injection of $10 \mathrm{nM} \mathrm{Fab} \mathrm{b12}$ or 447-52D and double referenced by subtracting a dual injection of HBS-EP+ followed by HBS-EP+. Fab with 4E10 Fv curves were generated by injecting $3 \mu \mathrm{M} 4 \mathrm{E} 10 \mathrm{Fv}$ ( $\sim 90 \mathrm{RUs}$ bound) followed by an 
Table 5. PhIP-Seq results for $4 \mathrm{E} 10 \mathrm{Fv}$.

\begin{tabular}{|c|c|c|c|c|c|}
\hline Rank & Avg. $-\log P$ & Peptide sequence & Peptide source & $\Phi$ & Charge \\
\hline \multirow[t]{2}{*}{1} & 12.25 & SKCRVFNTTERDEQGSKV & inositol 1,4,5-trisphosphate receptor type 2 & 0.17 & -1 \\
\hline & & NDFFQQTEDLYNEMKWQK & & & \\
\hline \multirow[t]{2}{*}{2} & 9.37 & PPPRCISTNKCTAPEVE & complement receptor type 1 isoform $S$ precursor & 0.48 & +1.9 \\
\hline & & NAIRVPGNRSFFSLTEIVR & & & \\
\hline \multirow[t]{2}{*}{3} & 7.32 & KAFNYRSYLTTHQRSHTG & zinc finger protein 267 & 0.18 & +4.1 \\
\hline & & ERPYKCEECGKAFNSRSY & & & \\
\hline \multirow[t]{2}{*}{4} & 7.22 & PPHELTEEEKQQILHSE & cytoplasmic dynein 1 intermediate chain 2 & 0.28 & -5.7 \\
\hline & & EFLSFFDHSTRIVERALSE & & & \\
\hline \multirow[t]{2}{*}{5} & 6.22 & AHTGEKPYVCRECGRGFR & Krueppel-related zinc finger protein 1 & 0.10 & +5.4 \\
\hline & & QHSHLVRHKRTHSGEKPY & & & \\
\hline \multirow[t]{2}{*}{6} & 5.21 & STPIEWYPDYEVEAYRRR & XP_373395.2 & 0.49 & -1.7 \\
\hline & & HHNSSLNFFNWFSDHNFA & & & \\
\hline \multirow[t]{2}{*}{7} & 4.72 & EQGIVGPRWWVFPSLRFAA & XP_498650.1 & 0.71 & +2 \\
\hline & & VSRPFCGAWVLSWGQAT & & & \\
\hline \multirow[t]{2}{*}{8} & 4.49 & GAQPPFDAQSPLDSQPQPS & nuclear fragile $\mathrm{X}$ mental retardation-interacting protein 1 & 0.42 & -0.9 \\
\hline & & GQPWNFHASTSWYWRQS & & & \\
\hline \multirow[t]{2}{*}{9} & 4.36 & LYEEISMPLLADVRLNYLG & inter- $\alpha$-trypsin inhibitor heavy chain $\mathrm{H} 6$ precursor & 0.74 & -2 \\
\hline & & GLVGASPWAVFPNYFGG & & & \\
\hline \multirow[t]{2}{*}{10} & 4.25 & YKVDVTWTRARGASRGWR & TP53-target gene 5 protein & 0.12 & +10.1 \\
\hline & & SRHQLKGRNGWRNSRVYK & & & \\
\hline \multirow[t]{2}{*}{11} & 4.15 & AKWREVSHTFSNYPPGVR & F-box only protein 44 isoform 1 & 0.58 & +1.3 \\
\hline & & YIWFQHGGVDTHYWAGWY & & & \\
\hline \multirow[t]{2}{*}{12} & 4.07 & MNPQIRNPMKAMYPGTFY & APOBEC-3C & 0.61 & +1 \\
\hline & & FQFKNLWEANDRNETWLC & & & \\
\hline \multirow[t]{2}{*}{13} & 3.78 & SGGYGSGGYGGSATPSGR & ATP-dep. RNA helicase A & 0.22 & +4 \\
\hline & & ICAGVGGGYRGVSRGGFR & & & \\
\hline \multirow[t]{2}{*}{14} & 3.77 & LMMKKRVRLEEAFEFVK & dual specificity protein phosphatase 4 isoform 2 & 0.48 & +4 \\
\hline & & QRRSIISPNFSFMGQLLQF & & & \\
\hline \multirow[t]{2}{*}{15} & 3.59 & DGMYQRFLRQHVHPEETG & ribonuclease 4 precursor & 0.28 & +2.1 \\
\hline & & GSDRYCNLMMQRRKMTLY & & & \\
\hline \multirow[t]{2}{*}{16} & 3.47 & TSLEVEPFASLTEAVRSS & NAD-dependent deacetylase sirtuin-3, mitochondrial isoform a & 0.56 & -0.9 \\
\hline & & VPRLLINRDLVGPLAWHP & & & \\
\hline \multirow[t]{2}{*}{17} & 3.40 & SEQFYDRSLGIMRRVLPP & secreted phosphoprotein 24 & 0.26 & +5.2 \\
\hline & & GNRRYPNHRHRARINTDF & & & \\
\hline \multirow[t]{2}{*}{18} & 3.38 & MKPGFSPRGGGFGGRGGF & rRNA 2'-O-methyltransferase fibrillarin & 0.03 & +7 \\
\hline & & GDRGGRGGRGGFGGGRGR & & & \\
\hline \multirow[t]{2}{*}{19} & 3.31 & NARRFSAGQWEARRGWRL & ribosomal biogenesis protein LAS1L isoform 1 & 0.43 & +2.9 \\
\hline & & FNCSASLDWPRMVESCLG & & & \\
\hline \multirow[t]{2}{*}{20} & 3.23 & ESWLSRFSYAWLAPLLAR & multidrug resistance-associated protein 7 isoform MRP7A & 0.51 & +2 \\
\hline & & GACGELRQPQDICRLPHR & & & \\
\hline
\end{tabular}

injection of $10 \mathrm{nM} \mathrm{Fab} \mathrm{b12} \mathrm{or} \mathrm{447-52D} \mathrm{in} \mathrm{the} \mathrm{presence} \mathrm{of} 3 \mu \mathrm{M}$ $4 \mathrm{E} 10 \mathrm{Fv}$ and double referenced by subtracting a dual injection of $3 \mu \mathrm{M} 4 \mathrm{E} 10 \mathrm{Fv}$ followed by $3 \mu \mathrm{M} 4 \mathrm{E} 10 \mathrm{Fv}$. Optimal regeneration was achieved by injection of $10 \mathrm{mM}$ glycine $(\mathrm{pH}=1.5)$ at a flow rate of $50 \mu \mathrm{L} /$ minute for 5 seconds followed by a 6 minute buffer stabilization phase. Sensorgrams were corrected by the doublesubtraction method [69] in Scrubber 2.0b software (BioLogic Software). Fig. 13 shows the second sample of each set of injections with baselines zeroed just prior to the second injection.

\section{Crystallization and crystallography}

Crystals of GEPs and 4E10 Fv were grown by the hanging-drop vapor diffusion method at $25^{\circ} \mathrm{C}$ with the following well solutions:

GEP 1: 25\% w/v PEG 3350, 0.2 M NaCl, 0.1 M Tris $(\mathrm{pH}=8.5)$ GEP 1/T117: unbuffered 12\% w/v PEG 8000, 0.1 M KCl, 5\% $\mathrm{v} / \mathrm{v}$ glycerol

GEP 2/T117: 1.6 $\mathrm{M} \mathrm{Li}_{2} \mathrm{SO}_{4}, 0.1 \mathrm{M}$ sodium acetate $(\mathrm{pH}=5.0)$ 
Table 6. PhIP-Seq results for GEP 2 Fv.

\begin{tabular}{|c|c|c|c|c|c|}
\hline Rank & Avg. $\log P$ & Peptide sequence & Peptide source & $\Phi$ & Charge \\
\hline \multirow[t]{2}{*}{1} & 8.35 & EGWQCSLCTYINNSELPY & zinc finger Ran-binding domain-containing protein 3 & 0.61 & -5.2 \\
\hline & & CEMCETPQGSAVMQIDSL & & & \\
\hline \multirow[t]{2}{*}{2} & 6.11 & PVFSFSKTSEYHDIMYPA & protein O-glucosyltransferase 1 precursor & 0.72 & -1.9 \\
\hline & & WTFWEGGPAVWPIYPTGL & & & \\
\hline \multirow[t]{2}{*}{3} & 5.74 & KVTDTKPRVAEWRYGPAR & transcription initiation factor TFIID subunit 1-like & 0.29 & -1 \\
\hline & & LWYDMLGVSEDGSGFDYG & & & \\
\hline \multirow[t]{2}{*}{4} & 5.58 & MTTFTEPEVVFLQSRGNE & arf-GAP domain and FG repeat-containing protein 2 & 0.56 & 0 \\
\hline & & VCRKIWLGLFDARTSLVP & & & \\
\hline \multirow[t]{2}{*}{5} & 5.57 & SGWGSRSQAPYGTLGAVS & $\begin{array}{l}\text { peroxisome proliferator-activated receptor } \gamma \\
\text { coactivator-related protein } 1\end{array}$ & 0.32 & -2.9 \\
\hline & & GGEQVLLHEEAGDSGFVS & & & \\
\hline \multirow[t]{2}{*}{6} & 5.05 & MGLSRRNPSYPWLWEDG & oxidized low-density lipoprotein receptor 1 isoform 1 & 0.53 & +2.1 \\
\hline & & SPLMPHLFRVRGAVSQTYP & & & \\
\hline \multirow[t]{2}{*}{7} & 4.90 & ASTLGSMPSFTARLTRGQL & RING finger protein 37 isoform a & 0.33 & +4.1 \\
\hline & & QHLGTRGSNTSWRPGTG & & & \\
\hline \multirow[t]{2}{*}{8} & 4.72 & QPNPHGNMMYTGPSHHSY & histone acetyltransferase KAT6A & 0.40 & +3.3 \\
\hline & & MNAAGVPKQSLNGPYMRR & & & \\
\hline \multirow[t]{2}{*}{9} & 4.62 & KLMGKDESTSRNRRSLSP & rho guanine nucleotide exchange factor 18 isoform a & 0.25 & +3.1 \\
\hline & & ILPGRHSPAPPPDPGFPA & & & \\
\hline \multirow[t]{2}{*}{10} & 4.47 & IQRYCNCNSSMPRPVKVA & phosphofurin acidic cluster sorting protein 1 & 0.54 & +4.9 \\
\hline & & AVGGQSYLSSILRFFVKS & & & \\
\hline \multirow[t]{2}{*}{11} & 4.44 & RYDVQERHPKGKMIPVLH & protein phosphatase 1 regulatory subunit 17 isoform 1 & 0.09 & +4.3 \\
\hline & & NTDLEQKKPRRKDTPALH & & & \\
\hline \multirow[t]{2}{*}{12} & 4.39 & RPGFAGPAVLDWEEWCPL & hyaluronidase-3 isoform 1 precursor & 0.58 & +1 \\
\hline & & WAGNWGRRRAYQAASWAW & & & \\
\hline \multirow[t]{2}{*}{13} & 4.39 & PIPSGSYYAPYGMPYTSM & SET-binding protein isoform a & 0.71 & 0 \\
\hline & & PMMNLGYYGQYPAPLYLS & & & \\
\hline \multirow[t]{2}{*}{14} & 4.28 & NQSQGCLPARTCHSPAHS & thrombospondin-3 isoform 1 precursor & 0.50 & +1.2 \\
\hline & & PCHIHAHCLFERNGAVSC & & & \\
\hline \multirow[t]{2}{*}{15} & 4.27 & LEREVTDVDSVVGRSSVG & dedicator of cytokinesis protein 8 isoform 1 & 0.11 & +1 \\
\hline & & ERRTLAQSRRLSERALSL & & & \\
\hline \multirow[t]{2}{*}{16} & 4.23 & RSRRKQHLLPPCVDEPEL & forkhead box protein $\mathrm{M} 1$ isoform 1 & 0.38 & +0.1 \\
\hline & & LFSEGPSTSRWAAELPFP & & & \\
\hline \multirow[t]{2}{*}{17} & 4.22 & TQAFDFYSRYFAPWVGVA & phenazine biosynthesis-like domain-containing protein, isoform a & 0.53 & -1.9 \\
\hline & & EDPVTGSAHAVLSSYWSQ & & & \\
\hline \multirow[t]{2}{*}{18} & 4.17 & TKWMNMKAVFGHPFSLGW & palmitoyltransferase ZDHHC3 isoform 2 & 0.52 & +1.1 \\
\hline & & ASPFATPDQGKADPYQYV & & & \\
\hline \multirow[t]{2}{*}{19} & 4.11 & AGSWHPRSYAAYALKTW & kiSS-1 receptor & 0.68 & +2.1 \\
\hline & & AHCMSYSNSALNPLLYAFL & & & \\
\hline \multirow[t]{2}{*}{20} & 4.07 & EETAGEPWEDGFEAELSP & NP_955358.1 & 0.31 & -5 \\
\hline & & VEQKLSALRSPLAQRPFF & & & \\
\hline
\end{tabular}

GEP 7: 20\% w/v PEG 2000, 0.2 M Trimethylamine N-oxide, 0.1 M Tris $(\mathrm{pH}=9.0)$

GEP 7/T117: 10\% w/v PEG 10000, 0.1 M NH 4 OAc, 0.1 M BisTris $(\mathrm{pH}=5.5)$

1C6: 3.5 M sodium formate, 0.1 M Bis-Tris Propane $(\mathrm{pH}=7.0)$

Crystals were cryopreserved in mother liquor containing 15\% v/v glycerol (GEP 1, GEP 1/T117, GEP 7/T117), mother liquor containing $10 \%$ (1C6) or 20\% (GEP 7) v/v glycerol, or 20\% w/w sucrose (GEP 2/T117). Diffraction data for GEP 1, 4E10, and 1C6 were collected at the Advanced Light Source beamline 5.0.2 (Lawrence Berkeley National Laboratory, Berkeley, CA) and reduced using HKL-2000 [70] or d*TREK (Rigaku) [71]. Diffraction data for GEP 7, GEP 1/T117, GEP 7/T117 and GEP 2/T117 were collected in house with $\mathrm{CuK} \alpha$ radiation on a R-AXIS IV++ image plate detector with HR optics (Rigaku) at 
Table 7. PhIP-Seq results for GEP 4 Fv.

\begin{tabular}{|c|c|c|c|c|c|}
\hline Rank & Avg. $-\log P$ & Peptide sequence & Peptide source & $\Phi$ & Charge \\
\hline \multirow[t]{2}{*}{1} & 16.36 & PKGKCLGSQDYLELANRF & $\begin{array}{l}S \text { phase cyclin A-associated protein in the } \\
\text { ER isoform a }\end{array}$ & 0.21 & +3 \\
\hline & & PQQAWEEARQFFLKKEKK & & & \\
\hline \multirow[t]{2}{*}{2} & 14.52 & RPGFAGPAVLDWEEWCPL & hyaluronidase-3 isoform 1 precursor & 0.58 & +1 \\
\hline & & WAGNWGRRRAYQAASWAW & & & \\
\hline \multirow[t]{2}{*}{3} & 13.98 & ISHIQPFSFLDLESLRSL & $\begin{array}{l}\text { leucine-rich repeat and fibronectin type-III } \\
\text { domain-containing protein } 2 \text { precursor }\end{array}$ & 0.50 & -1.8 \\
\hline & & HLDSNRLPSLGEDTLRGL & & & \\
\hline \multirow[t]{2}{*}{4} & 13.73 & EGWQCSLCTYINNSELPY & $\begin{array}{l}\text { zinc finger Ran-binding } \\
\text { domain-containing protein } 3\end{array}$ & 0.61 & -5.2 \\
\hline & & CEMCETPQGSAVMQIDSL & & & \\
\hline \multirow[t]{2}{*}{5} & 9.43 & LEQNLAAAEEGPLEPAVV & NP_957704.1 & 0.59 & -5.9 \\
\hline & & DAFNQAWHLFAHECPNYF & & & \\
\hline \multirow[t]{2}{*}{6} & 9.40 & QAAPAPQPVFVGPAVPQG & Krueppel-like factor 11 isoform a & 0.68 & 0 \\
\hline & & AVMLVLPQGALPPPAPCA & & & \\
\hline \multirow[t]{2}{*}{7} & 8.16 & EETAGEPWEDGFEAELSP & NP_955358.1 & 0.31 & -5 \\
\hline & & VEQKLSALRSPLAQRPFF & & & \\
\hline \multirow[t]{2}{*}{8} & 7.40 & SEALSRDPETLVGYSMVG & fatty acid synthase & 0.45 & 0 \\
\hline & & CQRAMMANRLSFFFDFRG & & & \\
\hline \multirow[t]{2}{*}{9} & 7.37 & RKREKCWGRSSVMAEYG & visual system homeobox 2 & 0.34 & +4 \\
\hline & & LYGAMVRHSIPLPESILKS & & & \\
\hline \multirow[t]{2}{*}{10} & 6.65 & LIKTKQRKESRFQLFMQ & rho guanine nucleotide exchange factor 11 isoform & 10.27 & +4 \\
\hline & & EAESHPQCRRLQLRDLIIS & & & \\
\hline \multirow[t]{2}{*}{11} & 6.06 & SDSSWQQQPGQPPPHSTW & uncharacterized protein C14orf43 & 0.38 & +0.2 \\
\hline & & NCHSLSLYSATKGSPHPG & & & \\
\hline \multirow[t]{2}{*}{12} & 5.98 & NGKIKYECNVCAKTFGQL & PR domain zinc finger protein 1 isoform 2 & 0.40 & +5 \\
\hline & & SNLKVHLRVHSGERPFKC & & & \\
\hline \multirow[t]{2}{*}{13} & 5.97 & KGKAGTPSGSSADEDTF & suppressor of cytokine signaling 6 & 0.11 & +2 \\
\hline & & SSSSAPIVFKDVRAQRPIR & & & \\
\hline \multirow[t]{2}{*}{14} & 5.75 & DEMKEIQERQRDKLYERR & transcriptional activator protein Pur- $\beta$ & -0.25 & -8 \\
\hline & & GGGSGGGEESEGEEVDED & & & \\
\hline \multirow[t]{2}{*}{15} & 5.64 & QPPFFSKEQPQALNFGGI & membrane metallo-endopeptidase-like 1 & 0.44 & -1.8 \\
\hline & & GMVIGHEITHGFDDNGRN & & & \\
\hline \multirow[t]{2}{*}{16} & 5.60 & RTTENPTLERKPYSSPR & zinc finger FYVE domain-containing protein 26 & 0.23 & +3 \\
\hline & & DSSLPALTSSALAFLKSRS & & & \\
\hline \multirow[t]{2}{*}{17} & 5.60 & NQSQGCLPARTCHSPAHS & thrombospondin-3 isoform 1 precursor & 0.50 & +1.2 \\
\hline & & PCHIHAHCLFERNGAVSC & & & \\
\hline \multirow[t]{2}{*}{18} & 5.29 & MAKKGCRHLVCSSGGNA & serine dehydratase-like & 0.48 & +5 \\
\hline & & GIAAAYAARKLGIPATIVL & & & \\
\hline \multirow[t]{2}{*}{19} & 5.28 & TTPFTLEGRPRGELHEQY & dedicator of cytokinesis protein 8 isoform 1 & 0.33 & +3.2 \\
\hline & & RRNTVLTTMHAFPYIKTR & & & \\
\hline \multirow[t]{2}{*}{20} & 5.26 & MSAQSLPAATPPTQKPPR & rho guanine nucleotide exchange factor 15 & 0.25 & +6 \\
\hline & & IIRPRPPSRSRAAQSPGP & & & \\
\hline
\end{tabular}

$-170^{\circ} \mathrm{C}$. Initial phase information for all data sets was determined by molecular replacement, as implemented in the CCP4i program suite [72-74], using 3LF6.pdb (T117), 3LH2.pdb (GEPs) and 1JP5.pbd (1C6) as initial search models. Phases were improved by subsequent rounds of model building and refinement using
COOT [75] and REFMAC [76]. Structure validation was carried out with PROCHECK [77], the MolProbity server [78], and the RCSB ADIT validation server. Data collection and structure refinement statistics are shown in Table 2. Crystals of GEP 2 alone could not be grown, despite considerable effort. 
Table 8. PhIP-Seq results for 1C6 Fv.

\begin{tabular}{|c|c|c|c|c|c|}
\hline Rank & Avg. $-\log P$ & Peptide sequence & Peptide source & $\Phi$ & Charge \\
\hline \multirow[t]{2}{*}{1} & 30.87 & AVLKYENNVMNIRQFNCS & Ser/Thr-protein phosphatase $2 B$ catalytic subunit $\alpha$ isoform 1 & 0.81 & 0 \\
\hline & & PHPYWLPNFMDVFTWSLP & & & \\
\hline \multirow[t]{2}{*}{2} & 14.67 & PTWDQVPPFQWSTSPFSG & putative phospholipase B-like 2 isoform 1 & 0.64 & +0.1 \\
\hline & & LLHMGQPDLWKFAPVKVS & & & \\
\hline \multirow[t]{2}{*}{3} & 13.63 & QGLVLNWGLMTTRGQGLM & Record removed (XP_495971.1) & 0.70 & +0.1 \\
\hline & & SSWGLGAHWGLPVNLGTG & & & \\
\hline \multirow[t]{2}{*}{4} & 13.54 & AGNHFINVMLSHPNHTGN & trans-2,3-enoyl-CoA reductase-like & 0.86 & +0.2 \\
\hline & & NACFPSPNYNPFTWMFFL & & & \\
\hline \multirow[t]{2}{*}{5} & 13.30 & PIPSGSYYAPYGMPYTSM & SET-binding protein isoform a & 0.71 & 0 \\
\hline & & PMMNLGYYGQYPAPLYLS & & & \\
\hline \multirow[t]{2}{*}{6} & 13.21 & MASNSSSCPTPGGGHLNG & retinoic acid receptor $\alpha$ isoform 1 & 0.69 & 0 \\
\hline & & YPVPPYAFFFPPMLGGLS & & & \\
\hline \multirow[t]{2}{*}{7} & 13.11 & MNPQIRNPMKAMYPGTFY & APOBEC-3C & 0.61 & +1 \\
\hline & & FQFKNLWEANDRNETWLC & & & \\
\hline \multirow[t]{2}{*}{8} & 12.85 & PENRGGFQGFGFGDGGF & E3 ubiquitin-protein ligase RNF185 isoform 1 & 0.61 & -1 \\
\hline & & QMSFGIGAFPFGIFATAFN & & & \\
\hline \multirow[t]{2}{*}{9} & 12.41 & MNHMLPDPGTWEEYFETFI & sulfotransferase $1 \mathrm{C} 2$ isoform a & 0.70 & -2.8 \\
\hline & & NGKVVWGSWFDHVKGWW & & & \\
\hline \multirow[t]{2}{*}{10} & 12.14 & LQPPPSRFKQFFCLSLPS & WD repeat-containing protein 27 isoform 1 & 0.73 & +1 \\
\hline & & SWDYSLPQLPWMVNSSSF & & & \\
\hline \multirow[t]{2}{*}{11} & 11.87 & TDRYMWSDASGLQECTKA & tectonin $\beta$-propeller repeat-containing protein 1 & 0.45 & -2 \\
\hline & & GTKPPSLQWAWVSDWFVD & & & \\
\hline \multirow[t]{2}{*}{12} & 11.46 & EYGPPRKQPKQQHGPGFW & uncharacterized protein $\mathrm{C} 12 \mathrm{orf} 12$ & 0.52 & +3 \\
\hline & & FQPPVCSNWGCWGGPWRP & & & \\
\hline \multirow[t]{2}{*}{13} & 10.84 & KVTDTKPRVAEWRYGPAR & transcription init. factor TFIID subunit 1-like & 0.29 & -1 \\
\hline & & LWYDMLGVSEDGSGFDYG & & & \\
\hline \multirow[t]{2}{*}{14} & 10.80 & EQGKEPWMVVREETGRWC & zinc finger protein 461 & 0.45 & -1.9 \\
\hline & & PGTWKTWGFHNNFLDNNE & & & \\
\hline \multirow[t]{2}{*}{15} & 10.57 & TYGEEGLKDGHQSSHGDI & dnaJ homolog subfamily B member 11 precursor & 0.33 & -2.7 \\
\hline & & FSHFFGDFGFMFGGTPRQ & & & \\
\hline \multirow[t]{2}{*}{16} & 10.26 & FWGTGLSLPSLPVSFPLQ & metallothionein-1E & 0.75 & +2 \\
\hline & & AFCPKFRWGRTAFFSWDT & & & \\
\hline \multirow[t]{2}{*}{17} & 9.46 & PVFSFSKTSEYHDIMYPA & protein O-glucosyltransferase 1 & 0.72 & -1.9 \\
\hline & & WTFWEGGPAVWPIYPTGL & & & \\
\hline \multirow[t]{2}{*}{18} & 9.45 & NTTWYSNDTWYGNDTWYG & sodium channel protein type 4 subunit $\alpha$ & 0.60 & -5 \\
\hline & & NEMWYGNDSWYANDTWNS & & & \\
\hline \multirow[t]{2}{*}{19} & 9.41 & STRLPSEYIYGFGEVEHTA & sucrase-isomaltase, intestinal & 0.42 & -0.9 \\
\hline & & FKRDLNWNTWGMFTRDQ & & & \\
\hline \multirow[t]{2}{*}{20} & 9.27 & SQWGQWSQVYGNPQQYGQ & nucleolysin TIAR isoform 1 & 0.59 & 0 \\
\hline & & YMANGWQVPPYGVYGQPW & & & \\
\hline
\end{tabular}

\section{PhIP-Seq analysis}

4E10, GEP and 1C6 Fvs were coupled to beads and analyzed in duplicate. For each $\mathrm{Fv}$ analyzed, $3 \mathrm{mg}$ of magnetic beads (Invitrogen M-270 Epoxy Dynabeads) were resuspended in $60 \mu \mathrm{L} 0.1 \mathrm{M} \mathrm{NaPO}_{4}(\mathrm{pH}=7.4)$. Beads were rocked at ambient temperature for $24 \mathrm{hrs}$ with $60 \mu \mathrm{g}$ of each $\mathrm{FV}$ in $1 \mathrm{M}\left(\mathrm{NH}_{4}\right)_{2} \mathrm{SO}_{4}$ and then washed with $10 \mathrm{mM}$ glycine in PBS to cap unreacted epoxy groups. Activity of $\mathrm{Fv}_{\mathrm{V}}$ coupled beads was confirmed by epitope-scaffold binding prior to PhIP-Seq analyses. PhIP-Seq analyses were performed as previously described $[17,50]$. Results were plotted as replicate $\# 1$ versus replicate $\# 2-\log _{10} P$-values; highly discordant, and therefore spurious, hits falling near the axes were excluded from analysis. 241 peptides were also discarded because they displayed nonspecific binding to all Abs tested [17]. Peptide hydrophobicity was determined with the Sigma-Aldrich PEPscreen Library Design Tool and overall charge at neutral $\mathrm{pH}$ was determined with the Innovagen Peptide Property Calculator. 


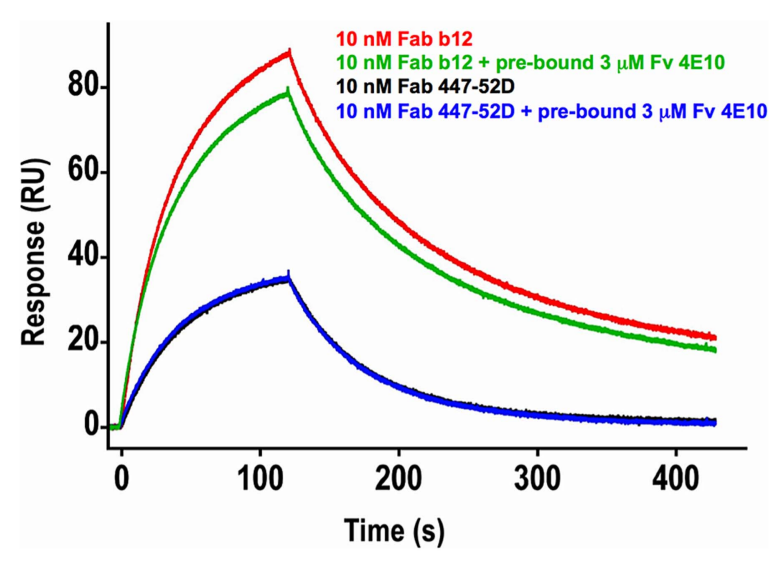

Figure 13. Effects of $4 \mathrm{E} 10 / \mathrm{gp} 140_{3}$ pre-binding on 447-52D and b12 binding. Double-corrected sensorgrams of the SPR response of $10 \mathrm{nM}$ analytes of Fab b12 (red and green traces) or Fab 447-52D (blue and black traces) to chip-coupled SF162 gp $140_{3}$ in the absence (red and black traces) or presence (green and blue traces) of pre-bound Fv 4E10 are shown. Fv 4E10, at a concentration of $3 \mu \mathrm{M}$, was flowed over the chip starting 5 minutes before the 447 or b12 injections and continued throughout the experiment. The black and blue 447-52D traces were completely superimposed, showing no effect of $4 \mathrm{E} 10$ pre-binding on 447-52D binding. While the dissociation phases of the b12 traces are nearly parallel, showing no minimal effect of 4 E10 pre-binding on the dissociation of b12 from the bound state, the association phases are clearly not parallel, resulting in a lower peak response in the presence of $4 \mathrm{E} 10$ pre-binding, showing a modest, but important, reduction in the association rate. This result suggests that the CD4 binding site adopted a distinct conformational state prior to b12 binding as a consequence of 4E10 binding at the MPER.

doi:10.1371/journal.ppat.1004403.g013

\section{Accession numbers}

Coordinates and structure factor amplitudes have been deposited in the Protein Data Bank [79] under accession codes:

\section{References}

1. Stephenson KE, Barouch DH (2013) A global approach to HIV-1 vaccine development. Immunol Rev 254: 295-304.

2. Haynes BF, McElrath MJ (2013) Progress in HIV-1 vaccine development. Curr Opin HIV AIDS 8: 326-332.

3. Bonsignori M, Alam SM, Liao HX, Verkoczy L, Tomaras GD, et al. (2012) HIV-1 antibodies from infection and vaccination: insights for guiding vaccine design. Trends Microbiol 20: 532-539.

4. Klein F, Mouquet H, Dosenovic P, Scheid JF, Scharf L, et al. (2013) Antibodies in HIV-1 vaccine development and therapy. Science 341: 1199-1204.

5. Stamatatos L (2012) HIV vaccine design: the neutralizing antibody conundrum. Curr Opin Immunol 24: 316-323.

6. Burton DR (2002) Antibodies, viruses and vaccines. Nat Rev Immunol 2: $706-$ 713.

7. Lang J, Jackson M, Teyton L, Brunmark A, Kane K, et al. (1996) B cells are exquisitely sensitive to central tolerance and receptor editing induced by ultralow affinity, membrane-bound antigen. J Exp Med 184: 1685-1697.

8. Qi H, Egen JG, Huang AY, Germain RN (2006) Extrafollicular activation of lymph node B cells by antigen-bearing dendritic cells. Science 312: 1672-1676.

9. Batista FD, Neuberger MS (1998) Affinity dependence of the B cell response to antigen: a threshold, a ceiling, and the importance of off-rate. Immunity 8: 751759 .

10. Kim M, Sun ZY, Rand KD, Shi X, Song L, et al. (2011) Antibody mechanics on a membrane-bound HIV segment essential for GP41-targeted viral neutralization. Nat Struct Mol Biol 18: 1235-1243.

11. Julien JP, Huarte N, Maeso R, Taneva SG, Cunningham A, et al. (2010) Ablation of the complementarity-determining region $\mathrm{H} 3$ apex of the anti-HIV-1 broadly neutralizing antibody $2 \mathrm{~F} 5$ abrogates neutralizing capacity without affecting core epitope binding. J Virol 84: 4136-4147.

12. Cardoso RM, Zwick MB, Stanfield RL, Kunert R, Binley JM, et al. (2005) Broadly neutralizing anti-HIV antibody $4 \mathrm{E} 10$ recognizes a helical conformation of a highly conserved fusion-associated motif in gp41. Immunity 22: 163-173.

13. Zwick MB, Labrijn AF, Wang M, Spenlehauer C, Saphire EO, et al. (2001) Broadly neutralizing antibodies targeted to the membrane-proximal external
4M8Q.pdb (ligand-bound GEP 1), 4LRN.pdb (unbound GEP 1), 4M62.pdb (ligand-bound GEP 2), 4ODX.pdb (ligand-bound GEP 7), 4OB5.pdb (unbound GEP 7), and 4LCI.pdb (1C6).

\section{Supporting Information}

Movie S1 Superposition of epitope binding site contacts from bound and unbound forms of 4E10. Residues from epitope binding site contacts are represented as mesh, pink for bound and yellow for unbound. The heavy chain GDR 1 and CDR3 loops are shown in cartoon representations with residues $\mathrm{W} 100 \mathrm{H}, \mathrm{W} 100 \mathrm{bH}$, and $\mathrm{F} 29 \mathrm{H}$ shown in licorice stick representations.

(M4V)

Movie S2 Superposition of epitope binding site contacts from bound and unbound forms of GEP 7. Residues from epitope binding site contacts are represented as mesh, pink for bound and yellow for unbound. The heavy chain CDR1 and CDR3 loops are shown in cartoon representations with residues $\mathrm{W} 100 \mathrm{H}, \mathrm{W100bH}$, and $\mathrm{F} 29 \mathrm{H}$ shown in licorice stick representations.

(M4V)

\section{Acknowledgments}

We would like to thank Tim Vanden Bos and Madeline LaPatra for assistance with protein production.

\section{Author Contributions}

Conceived and designed the experiments: KAKF DF HBL KL PDG SJE LS RKS. Performed the experiments: KAKF DF JJ MG MAH HBL AS KL. Analyzed the data: KAKF DF JJ MG MAH HBL AS KL PDG SJE LS RKS. Contributed reagents/materials/analysis tools: KAKF JJ MG HBL AS KL PDG SJE LS RKS. Wrote the paper: KAKF DF JJ MG HBL AS KL PDG SJE LS RKS.

region of human immunodeficiency virus type 1 glycoprotein gp41. J Virol 75: 10892-10905.

14. Binley JM, Wrin T, Korber B, Zwick MB, Wang M, et al. (2004) Comprehensive cross-clade neutralization analysis of a panel of anti-human immunodeficiency virus type 1 monoclonal antibodies. J Virol 78: 1323213252.

15. Correia BE, Ban YE, Holmes MA, Xu H, Ellingson K, et al. (2010) Computational design of epitope-scaffolds allows induction of antibodies specific for a poorly immunogenic HIV vaccine epitope. Structure 18: 1116-1126.

16. Larimore K, McCormick MW, Robins HS, Greenberg PD (2012) Shaping of Human Germline IgH Repertoires Revealed by Deep Sequencing. J Immunol 189(6): 3221-30.

17. Finton KA, Larimore K, Larman HB, Friend D, Correnti C, et al, (2013) Autoreactivity and exceptional CDR plasticity (but not unusual polyspecificity) hinder elicitation of the anti-HIV antibody 4E10. PLoS Pathog 9: e1003639.

18. Xu H, Song L, Kim M, Holmes MA, Kraft Z, et al. (2010) Interactions between lipids and human anti-HIV antibody $4 \mathrm{E} 10$ can be reduced without ablating neutralizing activity. J Virol 84: 1076-1088.

19. Doyle-Cooper G, Hudson KE, Cooper AB, Ota T, Skog P, et al. (2013) Immune tolerance negatively regulates $\mathrm{B}$ cells in knock-in mice expressing broadly neutralizing HIV antibody 4E10. J Immunol 191: 3186-3191.

20. Chen Y, Zhang J, Hwang KK, Bouton-Verville H, Xia SM, et al. (2013) Common tolerance mechanisms, but distinct cross-reactivities associated with gp41 and lipids, limit production of HIV-1 broad neutralizing antibodies 2F5 and 4E10. J Immunol 191: 1260-1275.

21. Ruprecht CR, Krarup A, Reynell L, Mann AM, Brandenberg OF, et al. (2011) MPER-specific antibodies induce gp120 shedding and irreversibly neutralize HIV-1. J Exp Med 208: 439-454.

22. Alam SM, Morelli M, Dennison SM, Liao HX, Zhang R, et al. (2009) Role of HIV membrane in neutralization by two broadly neutralizing antibodies. Proc Natl Acad Sci U S A 106: 20234-20239.

23. Amzel LM, Poljak RJ (1979) Three-dimensional structure of immunoglobulins. Ann Rev Biochem 48: 961-997. 
24. Wu TT, Kabat EA (1970) An analysis of the sequences of the variable regions of Bence Jones proteins and myeloma light chains and their implications for antibody complementarity. J Exp Med 132: 211-250.

25. Breden F, Lepik C, Longo NS, Montero M, Lipsky PE, et al. (2011) Comparison of antibody repertoires produced by HIV-1 infection, other chronic and acute infections, and systemic autoimmune disease. PLoS One 6: e16857.

26. Xiao X, Chen W, Feng Y, Zhu Z, Prabakaran P, et al. (2009) Germline-like predecessors of broadly neutralizing antibodies lack measurable binding to HIV1 envelope glycoproteins: implications for evasion of immune responses and design of vaccine immunogens. Biochem Biophys Res Commun 390: 404-409.

27. Scheid JF, Mouquet H, Ueberheide B, Diskin R, Klein F, et al. (2011) Sequence and structural convergence of broad and potent HIV antibodies that mimic CD4 binding. Science 333: 1633-1637.

28. Zhou T, Georgiev I, Wu X, Yang ZY, Dai K, et al. (2010) Structural basis for broad and potent neutralization of HIV-1 by antibody VRC01. Science 329: 811-817.

29. McGuire AT, Hoot S, Dreyer AM, Lippy A, Stuart A, et al. (2013) Engineering HIV envelope protein to activate germline $\mathrm{B}$ cell receptors of broadly neutralizing anti-CD4 binding site antibodies. J Exp Med 210: 655-663.

30. Bates JT, Keefer CJ, Utley TJ, Correia BE, Schief WR, et al. (2013) Reversion of somatic mutations of the respiratory syncytial virus-specific human monoclonal antibody Fab19 reveal a direct relationship between association rate and neutralizing potency. J Immunol 190: 3732-3739.

31. Wu X, Zhou T, Zhu J, Zhang B, Georgiev I, et al. (2011) Focused evolution of HIV-1 neutralizing antibodies revealed by structures and deep sequencing. Science 333: 1593-1602.

32. Johnson G, Wu TT (2000) Kabat database and its applications: 30 years after the first variability plot. Nucleic Acids Res 28: 214-218.

33. Johnson G, Wu TT (1998) Preferred CDRH3 lengths for antibodies with defined specificities. Int Immunol 10: 1801-1805.

34. Ma BJ, Alam SM, Go EP, Lu X, Desaire H, et al. (2011) Envelope deglycosylation enhances antigenicity of HIV-1 gp41 epitopes for both broad neutralizing antibodies and their unmutated ancestor antibodies. PLoS Pathog 7: e1002200

35. Foote J, Eisen HN (1995) Kinetic and affinity limits on antibodies produced during immune responses. Proc Natl Acad Sci U S A 92: 1254-1256.

36. Thomson CA, Bryson S, McLean GR, Creagh AL, Pai EF, et al. (2008) Germline V-genes sculpt the binding site of a family of antibodies neutralizing human cytomegalovirus. EMBO J 27: 2592-2602.

37. Scharf L, West AP, Jr., Gao H, Lee T, Scheid JF, et al. (2013) Structural basis for HIV-1 gp120 recognition by a germ-line version of a broadly neutralizing antibody. Proc Natl Acad Sci U S A 110: 6049-6054.

38. Wang F, Sen S, Zhang Y, Ahmad I, Zhu X, et al. (2013) Somatic hypermutation maintains antibody thermodynamic stability during affinity maturation. Proc Natl Acad Sci U S A 110: 4261-4266.

39. Lingwood D, McTamney PM, Yassine HM, Whittle JR, Guo X, et al. (2012) Structural and genetic basis for development of broadly neutralizing influenza antibodies. Nature 489: 566-570.

40. Schmidt AG, Xu H, Khan AR, O'Donnell T, Khurana S, et al. (2013) Preconfiguration of the antigen-binding site during affinity maturation of a broadly neutralizing influenza virus antibody. Proc Natl Acad Sci U S A 110: 264-269.

41. Wedemayer GJ, Patten PA, Wang LH, Schultz PG, Stevens RG (1997) Structural insights into the evolution of an antibody combining site. Science 276: 1665-1669.

42. Manivel V, Sahoo NC, Salunke DM, Rao KV (2000) Maturation of an antibody response is governed by modulations in flexibility of the antigen-combining site. Immunity 13: 611-620.

43. Babor M, Kortemme T (2009) Multi-constraint computational design suggests that native sequences of germline antibody H3 loops are nearly optimal for conformational flexibility. Proteins 75: 846-858.

44. Sethi DK, Agarwal A, Manivel V, Rao KV, Salunke DM (2006) Differential epitope positioning within the germline antibody paratope enhances promiscuity in the primary immune response. Immunity 24: 429-438.

45. Yin J, Beuscher AEt, Andryski SE, Stevens RC, Schultz PG (2003) Structural plasticity and the evolution of antibody affinity and specificity. J Mol Biol 330: 651-656.

46. Yin J, Mundorff EC, Yang PL, Wendt KU, Hanway D, et al. (2001) A comparative analysis of the immunological evolution of antibody $28 \mathrm{~B} 4$. Biochemistry 40: 10764-10773.

47. Nguven HP, Seto NO, MacKenzie CR, Brade L, Kosma P, et al. (2003) Germline antibody recognition of distinct carbohydrate epitopes. Nat Struct Biol 10: 1019-1025.

48. Pauling L (1940) Theory of the Structure and Process of Formation of Antibodies. J Am Chem Soc 62: 2643-2657.

49. Changeux JP, Edelstein S (2011) Conformational selection or induced fit? 50 years of debate resolved. F1000 Biol Rep 3: 19.

50. Larman HB, Zhao Z, Laserson U, Li MZ, Ciccia A, et al. (2011) Autoantigen discovery with a synthetic human peptidome. Nat Biotechnol 29: 535-541.

51. Blish CA, Nedellec R, Mandaliya K, Mosier DE, Overbaugh J (2007) HIV-1 subtype A envelope variants from early in infection have variable sensitivity to neutralization and to inhibitors of viral entry. AIDS 21: 693-702.
52. Cheng-Mayer C, Levy JA (1988) Distinct biological and serological properties of human immunodeficiency viruses from the brain. Ann Neurol 23 Suppl: S5861

53. Derby NR, Kraft Z, Kan E, Crooks ET, Barnett SW, et al. (2006) Antibody responses elicited in macaques immunized with human immunodeficiency virus type 1 (HIV-1) SF162-derived gp140 envelope immunogens: comparison with those elicited during homologous simian/human immunodeficiency virus SHIVSF162P4 and heterologous HIV-1 infection. J Virol 80: 8745-8762.

54. Davenport TM, Friend D, Ellingson K, Xu H, Caldwell Z, et al. (2011) Binding interactions between soluble HIV envelope glycoproteins and quaternarystructure-specific MAbs PG9 and PG16. J Virol 85: 7095-7107.

55. Correia BE, Ban YE, Friend DJ, Ellingson K, Xu H, et al. (2011) Computational protein design using flexible backbone remodeling and resurfacing: case studies in structure-based antigen design. J Mol Biol 405: 284-297.

56. Lawrence M, Colman PM (1993) Shape complementarity at protein/protein interfaces. J Mol Biol 234: 946-950.

57. Burton DR (2010) Scaffolding to build a rational vaccine design strategy. Proc Natl Acad Sci U S A 107: 17859-17860.

58. Graves SS, Stone DM, Loretz C, Peterson LJ, Lesnikova M, et al. (2011) Antagonistic and agonistic anti-canine CD28 monoclonal antibodies: tools for allogeneic transplantation. Transplantation 91: 833-840.

59. Gorny MK, Conley AJ, Karwowska S, Buchbinder A, Xu JY, et al. (1992) Neutralization of diverse human immunodeficiency virus type 1 variants by an anti-V3 human monoclonal antibody. J Virol 66: 7538-7542.

60. Roben P, Moore JP, Thali M, Sodroski J, Barbas CF, 3rd, et al. (1994) Recognition properties of a panel of human recombinant Fab fragments to the CD4 binding site of gp120 that show differing abilities to neutralize human immunodeficiency virus type 1. J Virol 68: 4821-4828.

61. Klein F, Diskin R, Scheid JF, Gaebler C, Mouquet H, et al. (2013) Somatic mutations of the immunoglobulin framework are generally required for broad and potent HIV-1 neutralization. Cell 153: 126-138.

62. Lavoie TB, Mohan S, Lipschultz CA, Grivel JC, Li Y, et al. (1999) Structural differences among monoclonal antibodies with distinct fine specificities and kinetic properties. Mol Immunol 36: 1189-1205.

63. Souto-Carneiro MM, Longo NS, Russ DE, Sun HW, Lipsky PE (2004) Characterization of the human Ig heavy chain antigen binding complementarity determining region 3 using a newly developed software algorithm, JOINSOLVER. J Immunol 172: 6790-6802.

64. Brochet X, Lefranc MP, Giudicelli V (2008) IMGT/V-QUEST: the highly customized and integrated system for IG and TR standardized V-J and V-D-J sequence analysis. Nucleic Acids Res 36: W503-508.

65. Giudicelli V, Chaume D, Lefranc MP (2004) IMGT/V-QUEST, an integrated software program for immunoglobulin and $\mathrm{T}$ cell receptor $\mathrm{V}-\mathrm{J}$ and $\mathrm{V}-\mathrm{D}-\mathrm{J}$ rearrangement analysis. Nucleic Acids Res 32: W435-440.

66. Wang X, Wu D, Zheng S, Sun J, Tao L, et al. (2008) Ab-origin: an enhanced tool to identify the sourcing gene segments in germline for rearranged antibodies. BMC Bioinformatics 9 Suppl 12: S20.

67. Volpe JM, Cowell LG, Kepler TB (2006) SoDA: implementation of a 3D alignment algorithm for inference of antigen receptor recombinations. Bioinformatics 22: 438-444.

68. Gaeta BA, Malming HR, Jackson KJ, Bain ME, Wilson P, et al. (2007) iHMMune-align: hidden Markov model-based alignment and identification of germline genes in rearranged immunoglobulin gene sequences. Bioinformatics 23: $1580-1587$.

69. Myszka DG (1999) Improving biosensor analysis. J Mol Recognit 12: 279-284.

70. Otwinowski Z, Minor W (1997) Processing of X-ray Diffraction Data Collected in Oscillation Mode. In: Jr CWC, Sweet RM, editors. Meth Enzymol. NY: Academic Press. pp. 307-326.

71. Pflugrath JW (1999) The finer things in X-ray diffraction data collection. Acta Crystallogr D Biol Crystallogr 55: 1718-1725.

72. McCoy AJ, Grosse-Kunstleve RW, Adams PD, Winn MD, Storoni LC, et al. (2007) Phaser crystallographic software. Journal of Applied Crystallography 40: 658-674.

73. Collaborative Computational Project N (1994) The CCP4 Suite: Programs for Protein Crystallography. Acta Cryst D50: 760-763.

74. Potterton E, Briggs P, Turkenburg M, Dodson E (2003) A graphical user interface to the CCP4 program suite. Acta Crystallogr D Biol Crystallogr 59: 1131-1137.

75. Emsley P, Cowtan K (2004) Coot: model-building tools for molecular graphics. Acta Crystallogr D Biol Crystallogr 60: 2126-2132.

76. Murshudov GN, Vagin AA, Dodson EJ (1997) Refinement of macromolecular structures by the maximum-likelihood method. Acta Crystallogr D Biol Crystallogr 53: 240-255.

77. Laskowski RA, MacArthur MW, Moss DS, Thornton JM (1993) PROCHECK: a program to check the stereochemical quality of protein structures. Journal of Applied Crystallography 26: 283-291.

78. Davis IW, Leaver-Fay A, Chen VB, Block JN, Kapral GJ, et al. (2007) MolProbity: all-atom contacts and structure validation for proteins and nucleic acids. Nucleic Acids Res 35: W375-383.

79. Berman HM, Westbrook J, Feng Z, Gilliland G, Bhat TN, et al. (2000) The Protein Data Bank. Nucleic Acids Research 28: 235-242.

80. Pettit FK, Bare E, Tsai A, Bowie JU (2007) HotPatch: a statistical approach to finding biologically relevant features on protein surfaces. J Mol Biol 369: 863879 . 